\title{
MHD EFFECTS ON NON-NEWTONIAN POWER-LAW FLUID PAST A CONTINUOUSLY MOVING POROUS FLAT PLATE WITH HEAT FLUX AND VISCOUS DISSIPATION
}

\author{
N. KISHAN \\ Department of Mathematics \\ University College of Science \\ Osmania University \\ Hyderabad - 7, A.P., INDIA \\ B. SHASHIDAR REDDY* \\ Department of Sciences and Humanities \\ Sreenidhi Institute of Science and Technology \\ Yamnampet, Ghatkesar, Ranga Reddy District - 501301, A.P., INDIA \\ E-mail: bsreddy_shashi@yahoo.com
}

\begin{abstract}
The problem of a magneto-hydro dynamic flow and heat transfer to a non-Newtonian power-law fluid flow past a continuously moving flat porous plate in the presence of sucion/injection with heat flux by taking into consideration the viscous dissipation is analysed. The non-linear partial differential equations governing the flow and heat transfer are transformed into non-linear ordinary differential equations using appropriate transformations and then solved numerically by an implicit finite difference scheme. The solution is found to be dependent on various governing parameters including the magnetic field parameter $M$, power-law index $n$, suction/injection parameter $f_{w}$, Prandtl number Pr and Eckert number Ec. A systematical study is carried out to illustrate the effects of these major parameters on the velocity profiles, temperature profile, skin friction coefficient and rate of heat transfer and the local Nusslet number.
\end{abstract}

Key words: magnetic field effects, non-Newtonian fluid, power-law index, viscous dissipation and suction/injection.

\section{Introduction}

The study of a non-Newtonian fluid has been of much interest to scientists because some industrial materials are non-Newtonian. In the food, polymer, petrochemical, rubber, paint and biological industries, fluids with non-Newtonian behaviors are encountered. The solution of the problem area of convective heat transfer between non-Newtonian fluids and two-dimensional or axisymmetric bodies is of general interest. Such a system has been analysed in the literature mainly for non-Newtonian power-law fluids and the effects of power-law index and generalized Prandtl number on the velocity and temperature fields as well as on the skin friction and heat transfer coefficients were emphasized. Acrivos (1960) was the first to study a freeconvection boundary-layer flow of a non-Newtonian power-law fluid along a vertical flat plate for large modified Prandtl numbers. Exact solutions of the equations of motion of power-law non-Newtonian fluids are difficult. The difficulty arises not only due to the non linearity but also due to the order of the differential equations.

The power-law model is widely used to study the pseudoplastic and dilatant nature of nonNewtonian fluids. The flow of a power-law fluid over a continuous moving flat plate with constant surface velocity and temperature was considered by Fox et al. (1969), who employed similarity and momentum

\footnotetext{
* To whom correspondence should be addressed
} 
integral methods. The solution of heat transfer to a non-Newtonian power-law fluid past a static and moving plate was considered by Acrivos et al. (1960), Schowalter (1960), Lee and Ames (1960) and Hisio-Tsung Lin and Yen-Ping Shih (1980).

A boundary-layer flow on a continuous moving solid surface in a Newtonian fluid was studied by Sakiadis (1961). The experimental results of Tsou et al. (1967) confirmed that the mathematically described boundary-layer problem on a continuous moving surface is physically reasonable. Howell et al. (1997) studied the momentum and heat transfer on a continuous moving surface in a power law fluid. Momentum and heat transfer in a power-law fluid with arbitrary injection/suction at a moving wall were studied by Rao et al. (1999).

Interest in hydro magnetic and heat transfer problems of non-Newtonian fluids has grown considerably in recent years because of their wide use in chemicals, foods, polymers, molten plastics, petroleum production and power engineering. For the non-Newtonian power-law fluids, the hydrodynamic problem of the MHD boundary layer flow over a continuously moving surface has been dealt with by several authors (e.g., Andersson et al. (1992), Cortell (2005) and Mahmoud and Mahmoud (2006)). In the above studies it was found that of the magnetic field decreases the velocity distribution and thus increases the skin friction coefficient. Sundaram and Nath (1976) considered the heat transfer to power-law fluid in the thermal entrance region with viscous dissipation and constant heat flux.

The effect of suction/injection is important in boundary layer control. Murthy and Sharma (1985) studied the effect of suction/injection on the flow past a continuously moving flat plate with heat flux. Recently Jadhav and Waghmode (1990) studied the effect of heat transfer to a non-Newtonian power-law fluid past a continuously moving porous flat plate with heat flux. The present work deals with the heat transfer to non-Newtonian power-law fluids past a continuously moving porous flat plate under the action of a transverse magnetic field with suction/injection by taking into account the effects of viscous dissipation.

\section{Mathematical analysis}

Consider the flow of a steady, laminar, incompressible non-Newtonian power-law fluid past a continuously moving porous flat plate. The $X$-axis is taken along the direction of the flow and the $y$-axis normal to it. The plate is assumed to be moving with uniform velocity $U$ in the presence of a transverse magnetic field with the magnetic field intensity $B_{0}$. The governing boundary layer equations are

$$
\begin{aligned}
& \frac{\partial u}{\partial x}+\frac{\partial u}{\partial y}=0 \\
& u \frac{\partial u}{\partial x}+v \frac{\partial u}{\partial y}=-\gamma \frac{\partial}{\partial y}\left[-\frac{\partial u}{\partial y}\right]^{n}-\frac{\sigma B_{0}^{2}}{\rho} u \\
& u \frac{\partial T}{\partial x}+v \frac{\partial T}{\partial y}=\alpha \frac{\partial^{2} T}{\partial y^{2}}+\mu\left[\frac{\partial u}{\partial y}\right]^{n+1}
\end{aligned}
$$

where $T$ is the temperature of the fluid, $\gamma=K / \rho$ is the kinematic viscosity, $K$ is the power-law fluid parameter, $\rho$ is density, $\alpha=k / \rho C_{p}$ is the thermal diffusivity, $k$ is the thermal conductivity, $C_{p}$ is the specific heat at a constant pressure, $\mu$ is the magnetic permeability, $\sigma$ is the electrical conductivity of the fluid and $n$ is the power-law fluid index. 
The boundary conditions associated with this problem can be expressed as

$$
\begin{aligned}
& u=U, \quad v=V_{0}(x), \quad \frac{\partial T}{\partial y}=-\frac{q_{w}}{k} \quad \text { at } \quad y=0, \\
& u=0, \quad v=0, \quad \frac{\partial T}{\partial y}=T_{\infty} \quad \text { as } \quad y \rightarrow \infty
\end{aligned}
$$

where $V_{0}(x)$ is the suction velocity and $q_{w}$ is the heat flux.

\section{Method of solution}

We shall transform Eqs (2.2) and (2.3) into a set of coupled ordinary differential equations amenable to a numerical solution. For this purpose we introduce a similarity transformation given as

$$
\begin{aligned}
& \eta=y\left(\frac{U^{2-n}}{\gamma x}\right)^{1 / n+1}, \\
& \psi(\eta)=\left(\gamma x U^{2 n-1}\right)^{1 / n+1} f(\eta), \\
& \theta(\eta)=\frac{k\left(T-T_{\infty}\right)}{q_{w}}\left(\frac{U^{2-n}}{\gamma x}\right)^{1 / n+1} .
\end{aligned}
$$

For obtaining the similarity solution the dimensionless stream function $\psi$ is defined as

$$
u=\frac{\partial \psi}{\partial y} \quad \text { and } \quad v=-\frac{\partial \psi}{\partial x}
$$

Using the similarity transformation in Eqs (2.2) and (2.3) they are transformed into the form

$$
\begin{aligned}
& n\left(-f^{\prime \prime}\right)^{n-1} f^{\prime \prime \prime}+\frac{1}{n+1} f f^{\prime \prime}-M f^{\prime}=0, \\
& \frac{1}{\mathrm{P}_{\mathrm{r}}} \theta^{\prime \prime}+\frac{1}{n+1}\left(f \theta^{\prime}-f^{\prime} \theta\right)+\mathrm{E}_{\mathrm{c}}\left(f^{\prime \prime}\right)^{n+1}=0
\end{aligned}
$$

where $M=\frac{\sigma B_{0}^{2}}{\rho U} x$ is the magnetic field parameter,

$\mathrm{P}_{\mathrm{r}}=\frac{U}{\alpha x}\left(\frac{U^{2-n}}{\gamma x}\right)^{\frac{-2}{n+1}}$ is the modified Prandtl number and

$\operatorname{Re}=\frac{U^{2-n} x^{n}}{\gamma}$ is the modified Reynolds number. 
The boundary conditions (2.4) are transformed into

$$
\begin{aligned}
& f(0)=-\frac{(n+1) V_{0}(x) \cdot \mathrm{Re}^{1 / n+1}}{U}=f_{w}, \\
& f^{\prime}(0)=1, \quad f^{\prime}(\infty)=0, \\
& \theta^{\prime}(0)=-1, \quad \theta(\infty)=0
\end{aligned}
$$

where $f_{w}>0$ for suction and $f_{w}<0$ for injection.

To solve the system of transformed governing Eqs (3.3) and (3.4) with the boundary conditions (3.5), first Eq.(3.3) is linearized using the quasi linearization technique (1965).

Then Eq.(3.3) is transformed to

$$
n\left[F^{\prime \prime \prime}\left(-f^{\prime \prime}\right)^{n-1}+f^{\prime \prime \prime}\left(-F^{\prime \prime}\right)^{n-1}-F^{\prime \prime \prime}\left(-F^{\prime \prime}\right)^{n-1}\right]+\frac{1}{n+1}\left[F f^{\prime \prime}+f F^{\prime \prime}-F F^{\prime \prime}\right]-M f^{\prime}=0
$$

where $F$ is assumed to be known and the above Eq.(3.6) can be expressed in the simplified form as

$$
A_{0} f^{\prime \prime \prime}+A_{2} f^{\prime \prime}+A_{3} f^{\prime}+A_{4} f=A_{5}-A_{1}\left[-f^{\prime \prime}\right]^{n-1}
$$

where

$$
\begin{aligned}
& A_{0}[i]=n\left(-F^{\prime \prime}\right)^{n-1}, \quad A_{1}[i]=n F^{\prime \prime \prime}, \\
& A_{3}[i]=-M, \\
& A_{4}[i]=\frac{1}{n+1} F^{\prime \prime}, \\
& A_{5}[i]=n F^{\prime \prime \prime}\left(-F^{\prime \prime}\right)^{n-1}+\frac{1}{n+1} F F^{\prime \prime} .
\end{aligned}
$$

Now Eq.(2.8) can be expressed in the simplified form as

$$
C_{0} \theta^{\prime \prime}+C_{1} \theta^{\prime}+C_{2} \theta+C_{3}=0
$$

where

$$
\begin{array}{ll}
C_{0}[i]=\frac{1}{\mathrm{P}_{\mathrm{r}}}, & C_{1}[i]=\frac{1}{n+1} F, \\
C_{2}[i]=\frac{-1}{n+1}, & C_{3}[i]=\mathrm{E}_{\mathrm{c}}\left(F^{\prime \prime}\right)^{n+1} .
\end{array}
$$

Using implicit finite difference formulae, Eqs (3.7) and (3.8) are transformed to

$$
\begin{aligned}
& B_{0}[i] f[i+2]+B_{1}[i] f[i+1]+B_{2}[i] f[i]+B_{3}[i] f[i-1]=B_{4}[i], \\
& D_{0}[i] \theta[i+1]+D_{1}[i] \theta[i]+D_{2}[i] \theta[i-1]+D_{3}[i]=0
\end{aligned}
$$

where

$$
\begin{aligned}
& B_{0}[i]=2 A_{0}[i], \quad B_{I}[i]=-6 A_{0}[i]+2 h A_{1}[i]+h^{2} A_{3}[i], \\
& B_{2}[i]=6 A_{0}[i]-4 h A_{2}[i]+2 h^{3} A_{4}[i], \quad B_{3}[i]=-2 A_{0}[i]+2 h A_{2}[i]-h^{2} A_{3}[i],
\end{aligned}
$$




$$
\begin{array}{ll}
B_{4}[i]=2 h^{3}\left\{A_{5}[i]-A_{1}\left[-F^{\prime \prime}[i]\right]^{n-1}\right\}, & \\
D_{0}[i]=2 C_{0}[i]+h C_{l}[i], & D_{I}[i]=-4 C_{0}[i]+2 h^{2} C_{2}[i], \\
D_{2}[i]=2 C_{0}[i]-h C_{l}[i], & D_{3}[i]=C_{3}[i],
\end{array}
$$

here ' $h$ ' represents the mesh size in $\eta$ direction. The system of Eqs (3.9) and (3.10) is solved under the boundary conditions (3.5) by the Gauss-Seidel iteration method and computations are carried out by using $C$ programming. The numerical solutions of $f$ are considered as $(n+1)^{\text {th }}$ order iterative solutions and $F$ are the $n^{\text {th }}$ order iterative solutions. After each cycle of iteration the convergence check is performed, and the process is terminated when $|F-f|<10^{6}$.

\section{Skin friction}

The shearing stress on the surface is defined by

$$
\tau_{w}=K\left[\left|\frac{\partial u}{\partial y}\right|^{n-1} \frac{\partial u}{\partial y}\right]_{y=0}
$$

Thus the skin friction coefficient is defined by

$$
C_{f}=\frac{2 \tau_{w}}{\rho U}=2 \operatorname{Re}_{x}^{\frac{-1}{n+1}}\left|f^{\prime \prime}(0)\right|^{n-1} f^{\prime \prime}(0) .
$$

\section{Heat transfer}

The local Nusselt number for heat transfer is defined by

$$
\mathrm{Nu}=\frac{x q_{w}}{k\left(T-T_{\infty}\right)}=\frac{\operatorname{Re}^{\frac{1}{n+1}}}{\theta(0)}
$$

where the heat flux at the wall is given by $q_{w}=-\left.k \frac{\partial T}{\partial y}\right|_{y=0}$.

\section{Results and discussions}

A parametric study is performed to explore the effects of the magnetic field parameter $M$, power-law fluid index $n$ and suction/injection parameter $f_{w}$ on the velocity distribution. The effects of the Eckert number $\mathrm{E}_{\mathrm{c}}$, power-law fluid index $n$, suction/injection parameter $f_{w}$, magnetic field parameter $M$ and Prandtl number $\mathrm{P}_{\mathrm{r}}$ on the velocity distribution $f^{\prime}$ and the temperature distribution were studied. The values of $\theta(\eta)$ and $\theta^{\prime}$ $(\eta)$ are tabulated for various values of the suction/injection parameter $f_{w}$. The values of skin friction coefficient $-f^{\prime \prime}(0)$ are tabulated for various values of the power-law index $n$, magnetic parameter $M$ and suction/injection parameter $f_{w}$. 
Table 1. Values of $\theta(\eta)$ for $n=1.0, \mathrm{P}_{\mathrm{r}}=0.7$.

\begin{tabular}{|c|c|c|c|c|c|c|c|}
\hline $\boldsymbol{\eta}$ & $\boldsymbol{f}_{\boldsymbol{w}}=\mathbf{- 0 . 5}$ & $\boldsymbol{f}_{\boldsymbol{w}}=\mathbf{- 0 . 2}$ & $\boldsymbol{f}_{\boldsymbol{w}}=\mathbf{- 0 . 1}$ & $\boldsymbol{f}_{\boldsymbol{w}}=\boldsymbol{0}$ & $\boldsymbol{f}_{\boldsymbol{w}}=\boldsymbol{0 . 1}$ & $\boldsymbol{f}_{\boldsymbol{w}}=\mathbf{0 . 2}$ & $\boldsymbol{f}_{\boldsymbol{w}}=\mathbf{0 . 5}$ \\
\hline 0 & 1.857265 & 1.734594 & 1.694947 & 1.655879 & 1.617355 & 1.579337 & 1.468332 \\
\hline 0.5 & 1.414673 & 1.298594 & 1.261162 & 1.224315 & 1.188018 & 1.152232 & 1.047956 \\
\hline 1.0 & 1.073467 & 0.971128 & 0.938196 & 0.905812 & 0.873941 & 0.842546 & 0.751275 \\
\hline 1.5 & 0.813776 & 0.726951 & 0.699022 & 0.671566 & 0.644555 & 0.617959 & 0.540796 \\
\hline 2.0 & 0.616891 & 0.544736 & 0.52151 & 0.498679 & 0.476223 & 0.454124 & 0.390179 \\
\hline 2.5 & 0.467301 & 0.40807 & 0.388992 & 0.370246 & 0.35182 & 0.333706 & 0.281504 \\
\hline 3.0 & 0.353056 & 0.304909 & 0.289406 & 0.274189 & 0.259252 & 0.244593 & 0.202584 \\
\hline 3.5 & 0.265281 & 0.226571 & 0.214127 & 0.201933 & 0.189988 & 0.178294 & 0.14501 \\
\hline 4.0 & 0.197473 & 0.166792 & 0.156958 & 0.147343 & 0.137949 & 0.12878 & 0.102884 \\
\hline 4.5 & 0.144856 & 0.121009 & 0.113395 & 0.105971 & 0.09874 & 0.091706 & 0.072002 \\
\hline 5.0 & 0.103888 & 0.085853 & 0.080122 & 0.07455 & 0.069141 & 0.063898 & 0.049336 \\
\hline 6.0 & 0.071911 & 0.058809 & 0.054667 & 0.050653 & 0.046769 & 0.043018 & 0.032689 \\
\hline 6.5 & 0.046911 & 0.037981 & 0.035174 & 0.032461 & 0.029846 & 0.027329 & 0.020457 \\
\hline 7.0 & 0.027341 & 0.021928 & 0.020235 & 0.018605 & 0.017038 & 0.015536 & 0.011467 \\
\hline 7.5 & 0.012012 & 0.009549 & 0.008782 & 0.008046 & 0.007342 & 0.006668 & 0.004858 \\
\hline
\end{tabular}

Table 2. Values of $-\theta^{\prime}(\eta)$ for $n=1.0, \mathrm{P}_{\mathrm{r}}=0.7$.

\begin{tabular}{|c|c|c|c|c|c|c|c|}
\hline $\boldsymbol{\eta}$ & $\boldsymbol{f}_{\boldsymbol{w}}=\mathbf{- 0 . 5}$ & $\boldsymbol{f}_{\boldsymbol{w}}=\mathbf{- 0 . 2}$ & $\boldsymbol{f}_{\boldsymbol{w}}=\mathbf{- 0 . 1}$ & $\boldsymbol{f}_{\boldsymbol{w}}=\boldsymbol{0}$ & $\boldsymbol{f}_{\boldsymbol{w}}=\mathbf{0 . 1}$ & $\boldsymbol{f}_{\boldsymbol{w}}=\mathbf{0 . 2}$ & $\boldsymbol{f}_{\boldsymbol{w}}=\mathbf{0 . 5}$ \\
\hline 0 & 1 & 1 & 1 & 1 & 1 & 1 & 1 \\
\hline 0.5 & 0.778965 & 0.756885 & 0.749568 & 0.742276 & 0.735009 & 0.727767 & 0.706156 \\
\hline 1.0 & 0.595929 & 0.56572 & 0.555915 & 0.54623 & 0.536658 & 0.52719 & 0.499289 \\
\hline 1.5 & 0.452251 & 0.421677 & 0.411858 & 0.402198 & 0.392682 & 0.383291 & 0.355703 \\
\hline 2.0 & 0.343053 & 0.315368 & 0.306494 & 0.297763 & 0.289157 & 0.280657 & 0.255638 \\
\hline 2.5 & 0.261265 & 0.237285 & 0.229571 & 0.221966 & 0.214455 & 0.20702 & 0.185095 \\
\hline 3.0 & 0.200131 & 0.17967 & 0.173052 & 0.166516 & 0.160049 & 0.153641 & 0.134752 \\
\hline 3.5 & 0.154199 & 0.136791 & 0.131139 & 0.125552 & 0.120022 & 0.114545 & 0.098467 \\
\hline 4.0 & 0.119404 & 0.10459 & 0.099774 & 0.095017 & 0.090316 & 0.085668 & 0.072124 \\
\hline 4.5 & 0.092824 & 0.080217 & 0.076126 & 0.072094 & 0.068121 & 0.064206 & 0.052908 \\
\hline 5.0 & 0.07237 & 0.061657 & 0.058196 & 0.054797 & 0.05146 & 0.048187 & 0.038847 \\
\hline 6.0 & 0.056539 & 0.047461 & 0.044547 & 0.041697 & 0.038913 & 0.036196 & 0.028539 \\
\hline 6.5 & 0.044233 & 0.036568 & 0.034128 & 0.031752 & 0.029443 & 0.027204 & 0.020973 \\
\hline 7.0 & 0.034637 & 0.028193 & 0.026159 & 0.02419 & 0.022287 & 0.020452 & 0.015416 \\
\hline 7.5 & 0.027138 & 0.021744 & 0.020058 & 0.018434 & 0.016874 & 0.015379 & 0.011332 \\
\hline
\end{tabular}


Table 3. Values of Skin friction coefficient $-f^{\prime \prime}(0)$.

\begin{tabular}{|l|c|c|c|}
\hline \multirow{4}{*}{$\boldsymbol{N}$} & $\boldsymbol{M}$ & \multicolumn{2}{|c|}{ Value of $-f^{\prime \prime}(0)$} \\
\cline { 2 - 4 } & 0 & $\boldsymbol{f}_{\boldsymbol{w}}=\mathbf{- 0 . 5}$ & $\boldsymbol{f}_{\boldsymbol{w}}=\mathbf{0 . 5}$ \\
\hline \multirow{4}{*}{0.5} & 1 & 0.596917 & 1.253879 \\
\cline { 2 - 4 } & 2 & 1.279080 & 2.159345 \\
\cline { 2 - 4 } & 5 & 1.923370 & 2.995336 \\
\cline { 2 - 4 } & 10 & 3.638935 & 5.217111 \\
\hline \multirow{4}{*}{1.0} & 0 & 6.148195 & 8.516776 \\
\cline { 2 - 4 } & 1 & 0.632489 & 0.894868 \\
\cline { 2 - 4 } & 2 & 1.056957 & 1.322353 \\
\cline { 2 - 4 } & 5 & 1.405144 & 1.673162 \\
\hline \multirow{4}{*}{1.5} & 10 & 2.207136 & 2.481687 \\
\cline { 2 - 4 } & 0 & 3.176641 & 3.459632 \\
\cline { 2 - 4 } & 1 & 0.643933 & 0.808752 \\
\cline { 2 - 4 } & 2 & 0.978565 & 1.122177 \\
\cline { 2 - 4 } & 5 & 1.228189 & 1.360548 \\
\hline & 10 & 1.755488 & 1.870430 \\
\hline & & 2.334368 & 2.435672 \\
\hline
\end{tabular}

Table 1 shows that temperature $\theta(\eta)$ decreases with the increase in the suction and it increases with the increase in the injection for $n=1.0, \mathrm{P}_{\mathrm{r}}=0.7$ and $\mathrm{E}_{\mathrm{c}}=0$. Table 2 shows that the effect of injection and suction is to decrease the rate of heat transfer $-\theta^{\prime}(\eta)$. The values of the skin friction coefficient $-f^{\prime \prime}(0)$ for different values of the magnetic field parameter $M$ and power-law fluid index $\mathrm{n}$ for $f_{w}=-0.5$ (injection) and $f_{w}=0.5$ (suction) are tabulated in Tab.3. It is evident from the table that an increase in the magnetic field parameter $\mathrm{M}$ increases the skin friction coefficient value $-f^{\prime \prime}(0)$ in both the cases of suction and injection for pseudo plastic, Newtonian and dilatant fluids. It can also be noticed that an increase in the power-law index decreases the skin friction coefficient value $-f^{\prime \prime}(0)$.

The effects of suction and injection on the velocity profiles $f^{\prime}$ for pseudo plastic and dilatant fluids are shown in the Fig.1. It is evident from the figures that an increase in suction leads to a decrease in the velocity, while the velocity increases with an increase in the injection. The effects of the magnetic field parameter $M$ on the velocity profiles for pseudo plastic fluids in Fig.2 and for dilatant fluids in Fig.3 are plotted for both the cases of suction and injection. It is noticed from the figures that the effect of the magnetic field is to decrease the velocity profiles $f^{\prime}$ for suction and injection in both the cases of pseudo plastic and dilatant fluids. It is also seen from above figures that the magnetic field effect is greater in suction when compared to injection. 

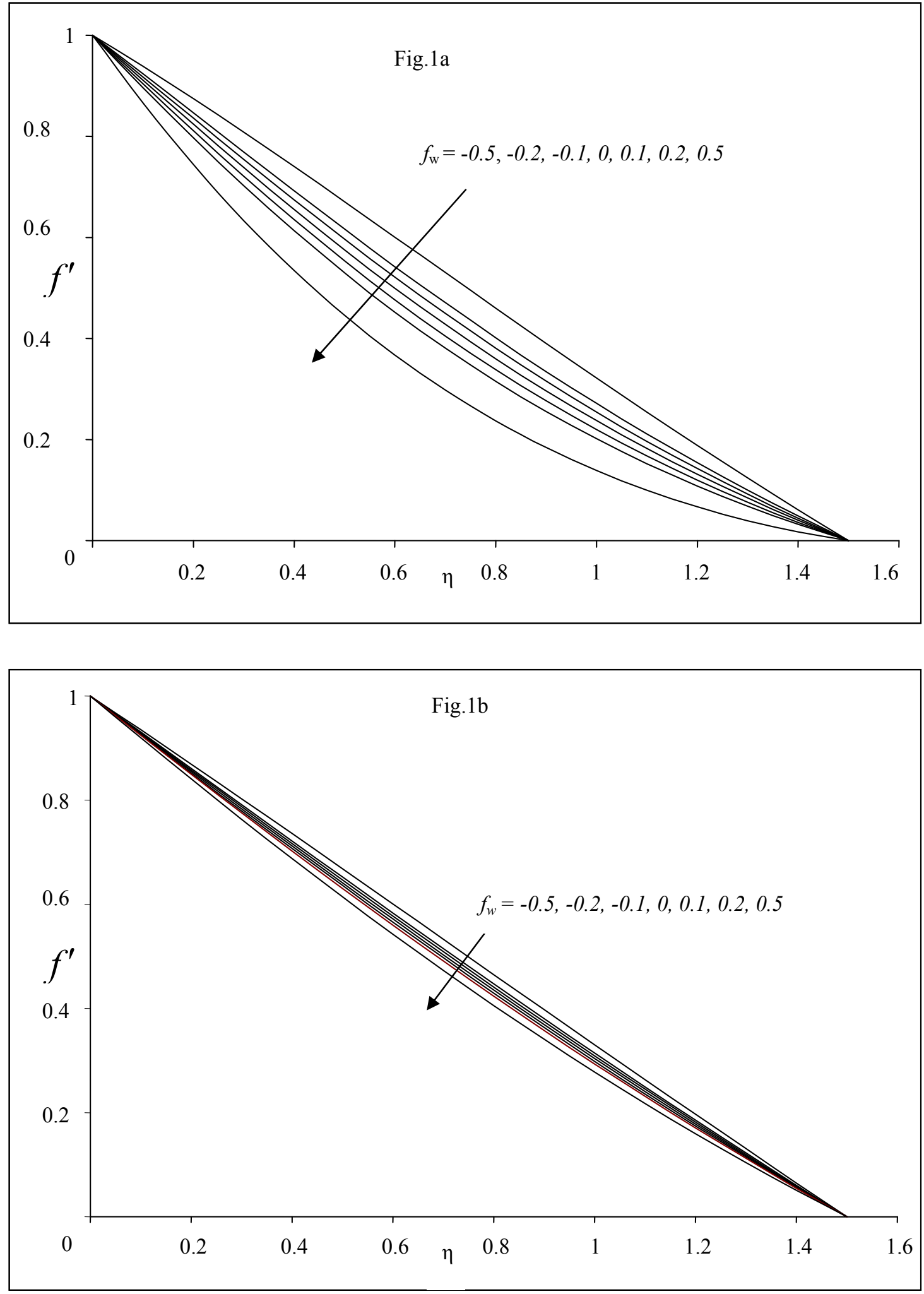

Fig.1. Variation of velocity profiles $f^{\prime}$ with $M=0$ for different values of suction parameter $f_{w}$. (a) $n=0.5$ (pseudo plastic fluid) and (b) $n=1.5$ (dilatant fluid). 

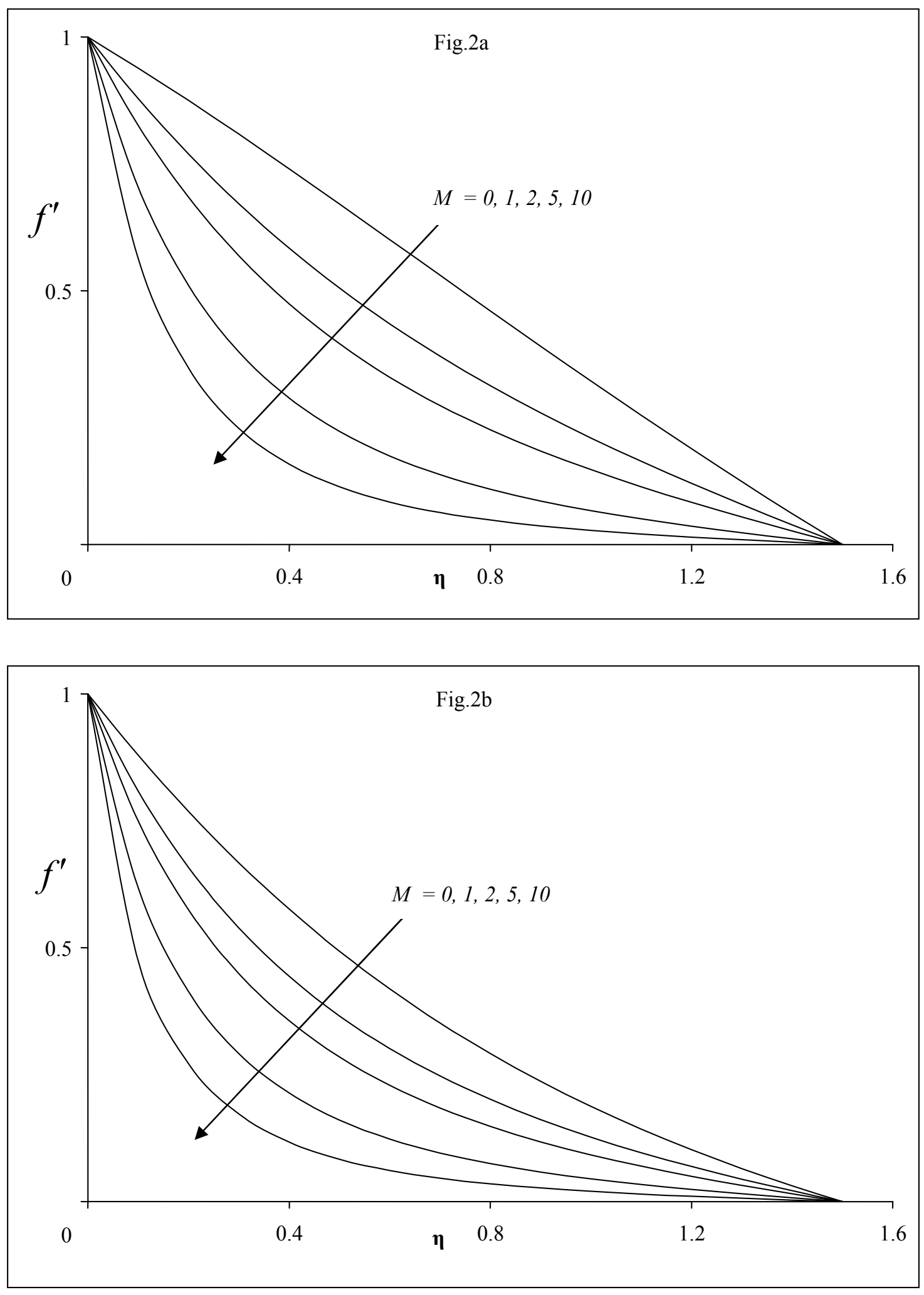

Fig.2. Variation of velocity profiles $f^{\prime}$ with $n=0.5$ (pseudo plastic fluid) for different values of magnetic parameter $M$. (a) $f_{w}=-0.5$ (injection) and (b) $f_{w}=0.5$ (suction). 

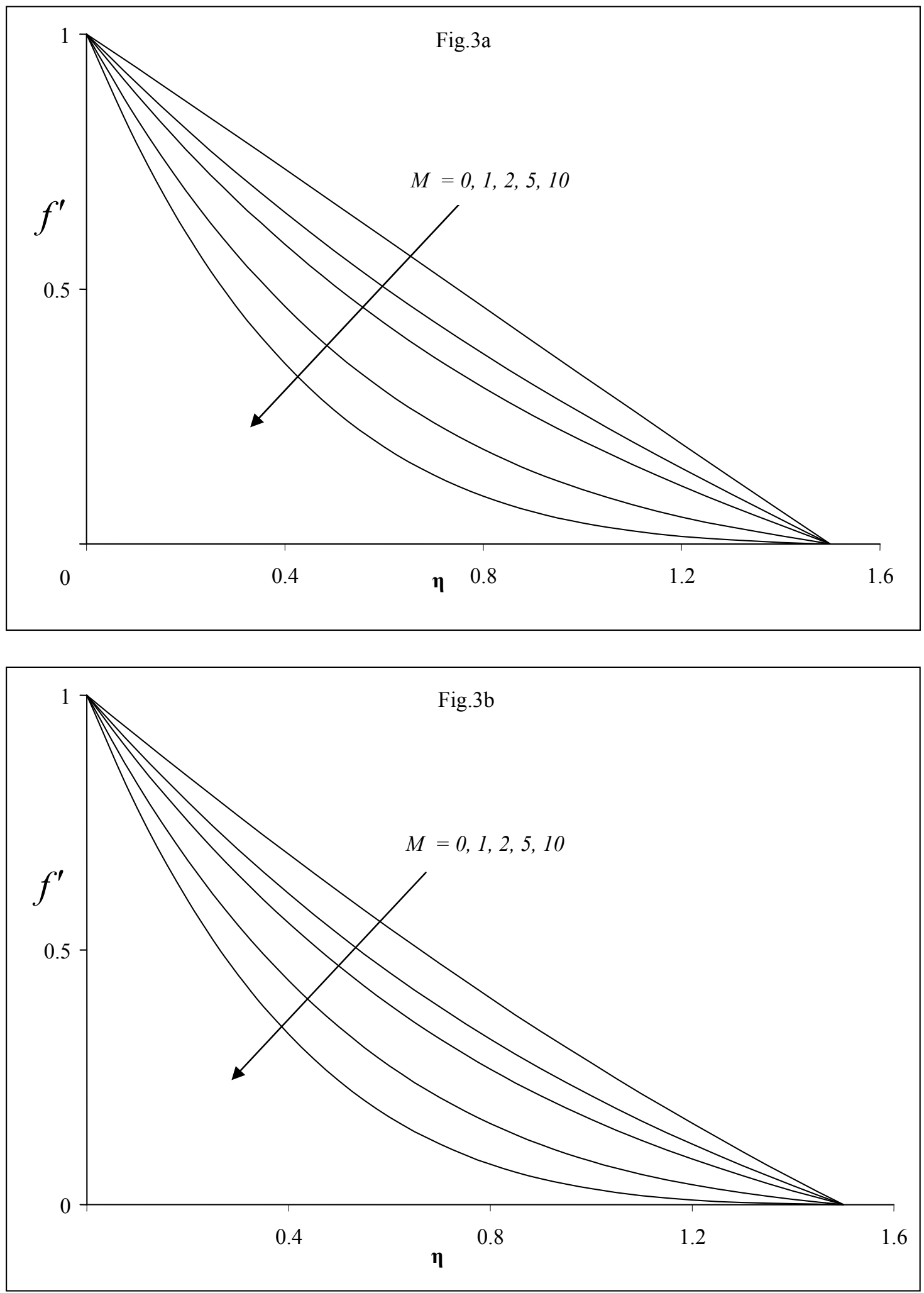

Fig.3. Variation of velocity profiles $f^{\prime}$ with $n=1.5$ (dilatant fluid) for different values of magnetic parameter $M$.

(a) $f_{w}=-0.5$ (injection) and (b) $f_{w}=0.5$ (suction). 
The effect of the power-law fluid index $n$ is to increase the velocity and temperature profiles which can be observed from Figs 4 and 5. Figure 6 shows that the temperature decreases with an increase in suction, while the reverse phenomenon occurs with injection for both pseudo plastic and dilatant fluids. The comparison of temperature profiles $\theta$ in Fig. $7 \mathrm{a}$ and the rate of heat transfer $-\theta^{\prime}(\eta)$ in Fig. $7 \mathrm{~b}$ with respect to suction and injection for Newtonian and non-Newtonian fluids is shown. It follows from the figures that the temperature increases with the power-law fluid index $n$ for both the cases of suction and injection parameter. And the rate of heat transfer $-\theta^{\prime}(\eta)$ increases with an increase in the power-law fluid index $n$. It can also be seen that the temperature profiles $\theta$ and the rates of heat transfer $-\theta^{\prime}(\eta)$ for Newtonian and non-Newtonian fluids with suction are higher when compared with injection. Figures 8 and 9 show the effect of the Eckert number on the temperature profiles. With a very small increase in the Eckert number $\mathrm{E}_{\mathrm{c}}$ temperature profiles increase rapidly with suction/ injection for both the cases of pseudo plastic and dilatant fluids. The temperature distributions of pseudo plastic fluids and dilatant fluids are presented for selected values of the magnetic field parameter $M$ in Fig. 10 and Fig.11 respectively. It is clear from these figures that the magnetic field increases the temperature distribution for both the cases of suction and injection. Also, the influence is more significant in the case of injection. Figures 12 and 13 present the temperature profiles for various values of the Prandtl number $P_{r}$ respectively, for pseudo plastic fluids and dilatant fluids. It is evident from these figures that the increase in the Prandtl number Pr decreases the temperature distribution for both the cases of suction and injection. This behavior is more noticeable for suction.

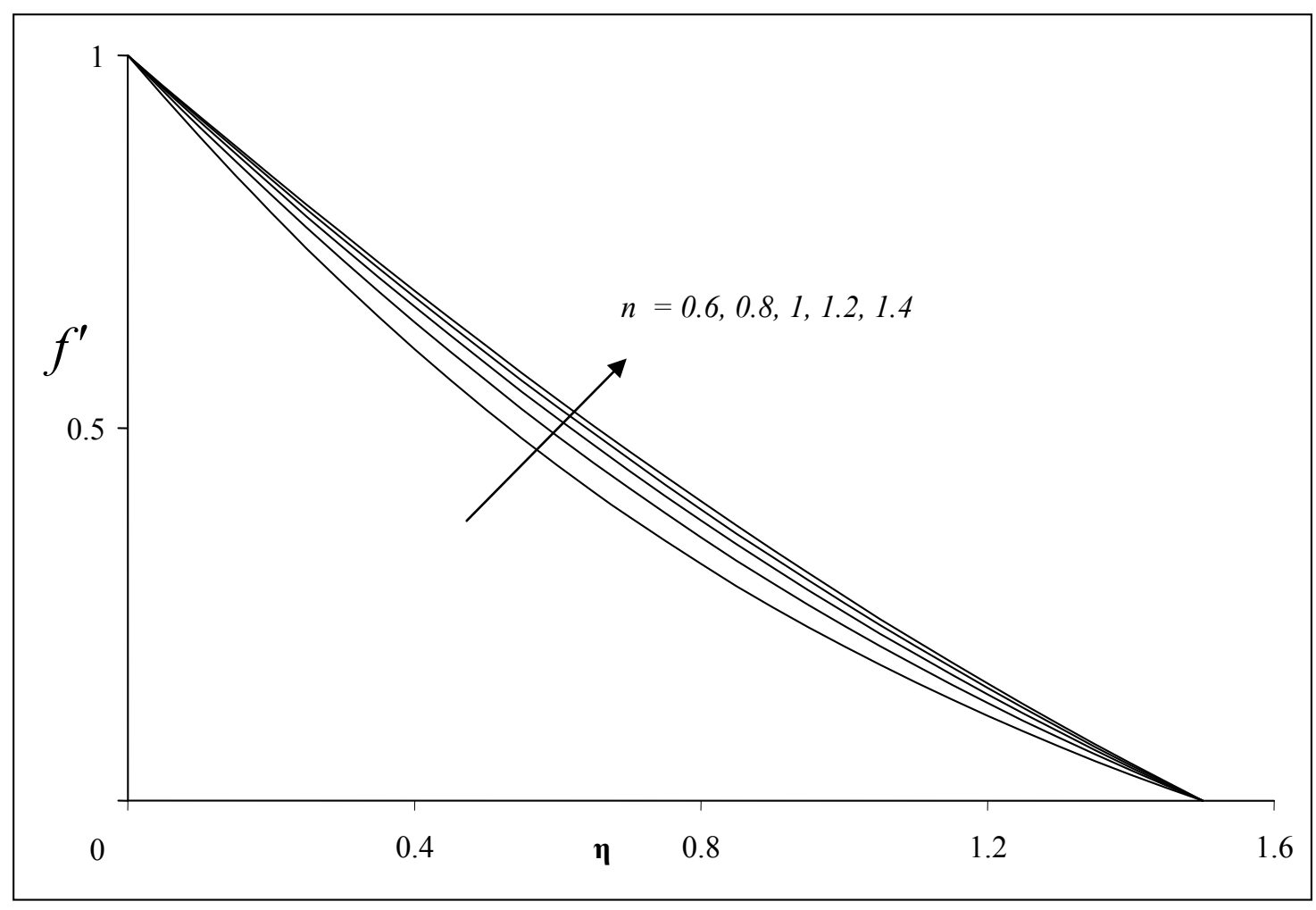

Fig.4. Variation of velocity profiles $f^{\prime}$ with $M=0$ and $f_{w}=0.5$ for different values of power-law index $n$. 


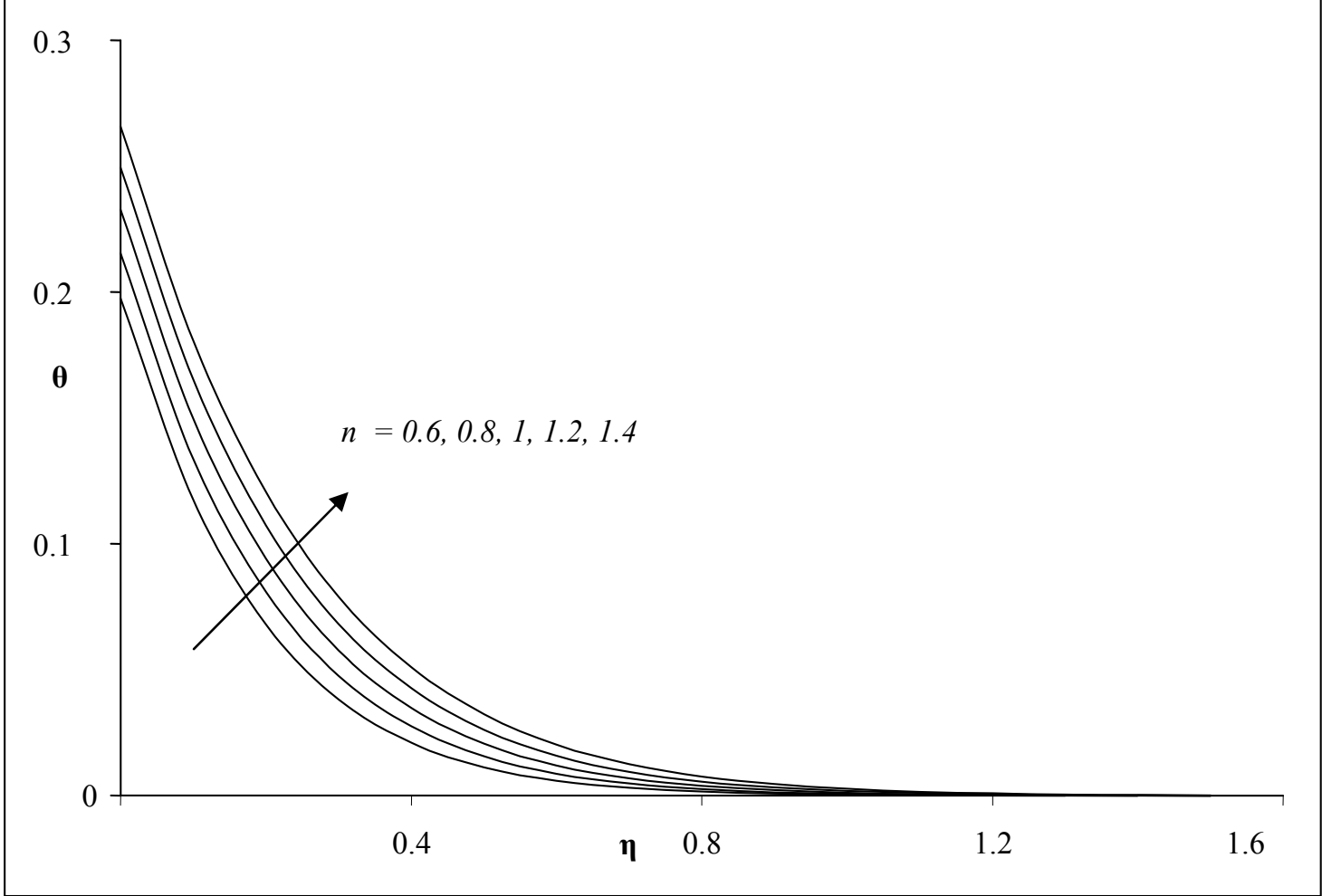

Fig.5. Variation of temperature profiles $g$ with $M=0, \mathrm{Ec}=0, \operatorname{Pr}=10$ and $f_{w}=0.5$ for different values of power-law index $n$.

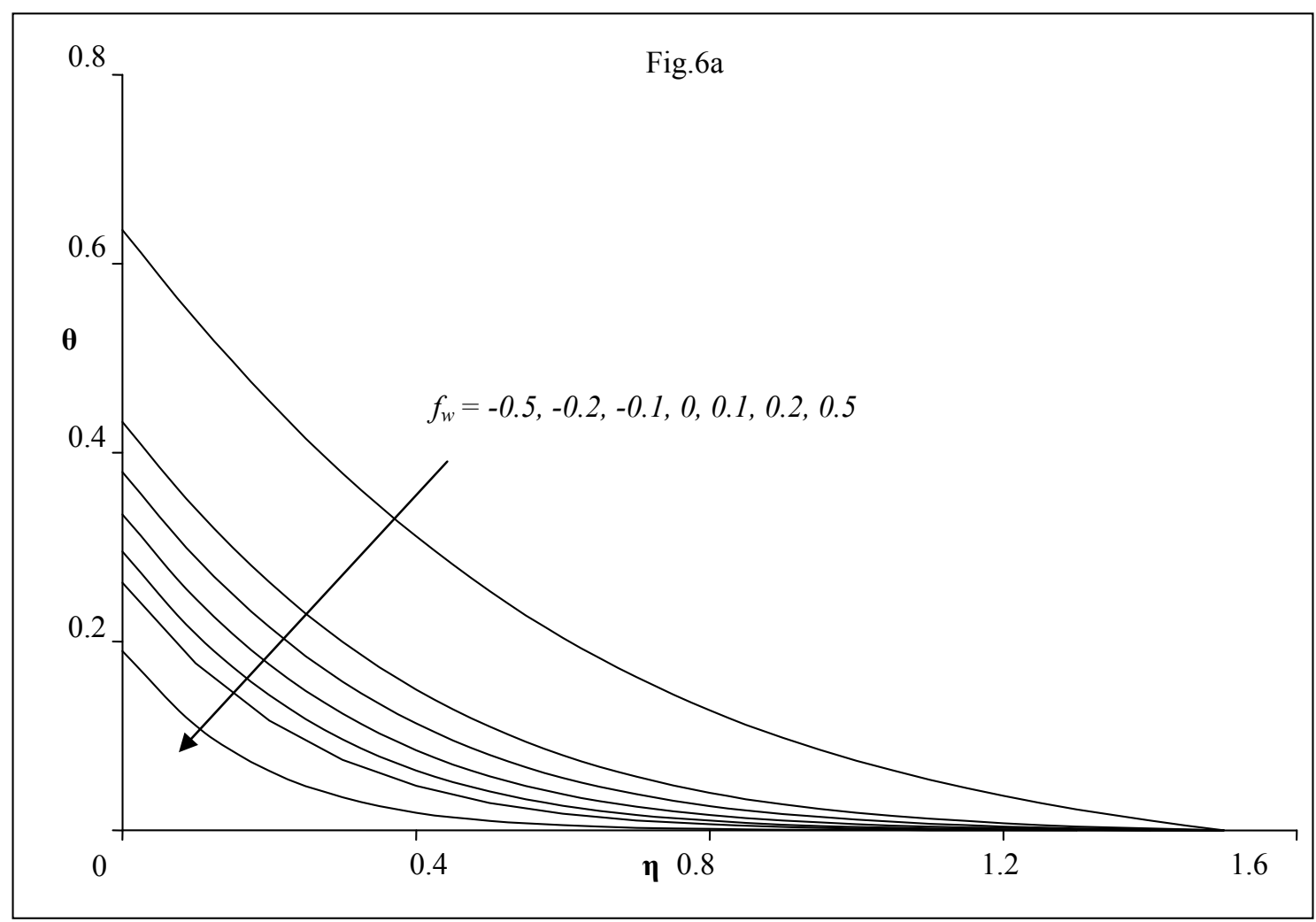




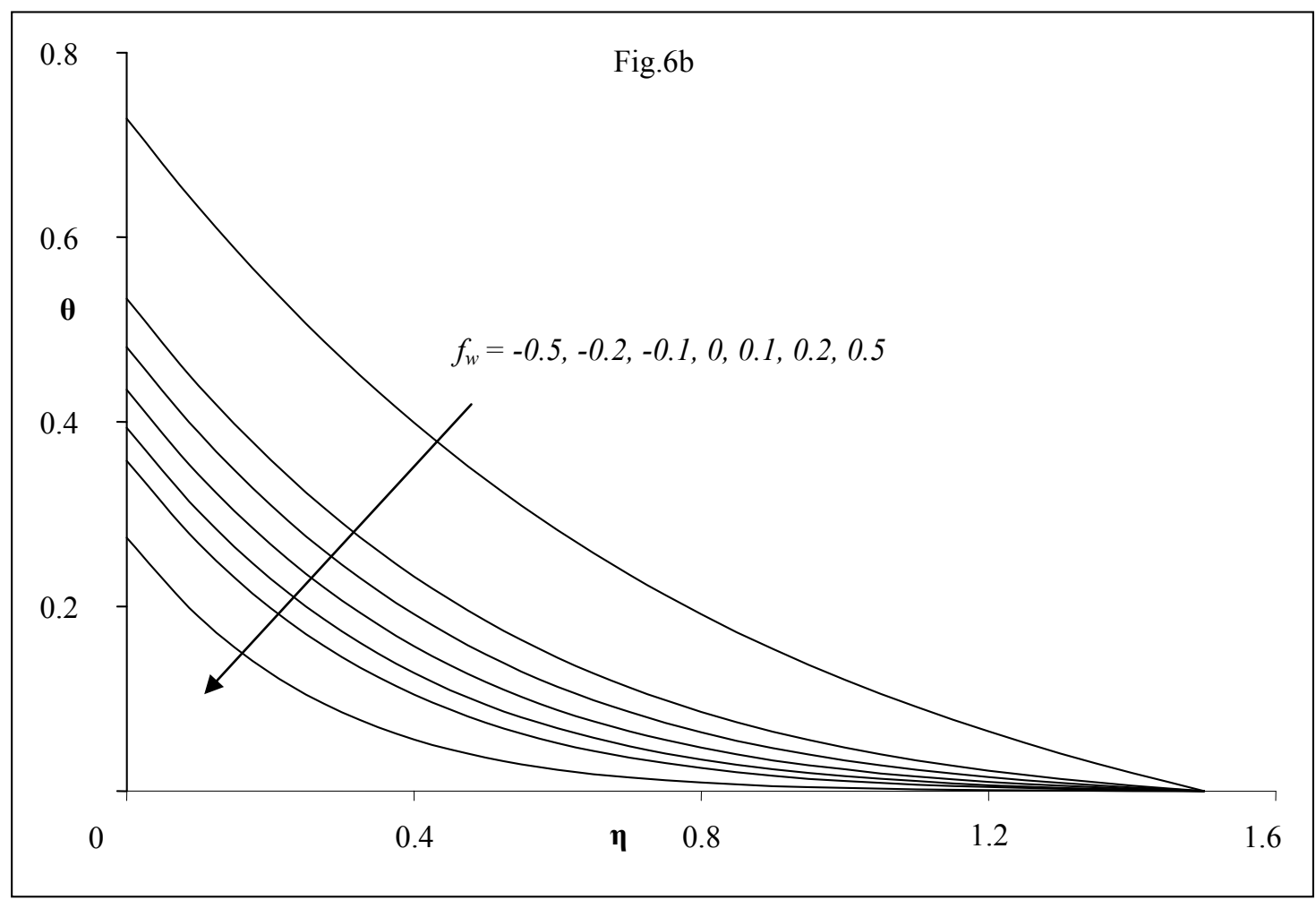

Fig.6. Variation of temperature profiles $g$ with $M=0, \mathrm{Ec}=0, \operatorname{Pr}=10$ for different values of suction parameter $f_{w}$. (a) $n=0.5$ (pseudo plastic fluid) and (b) $n=1.5$ (dilatant fluid).

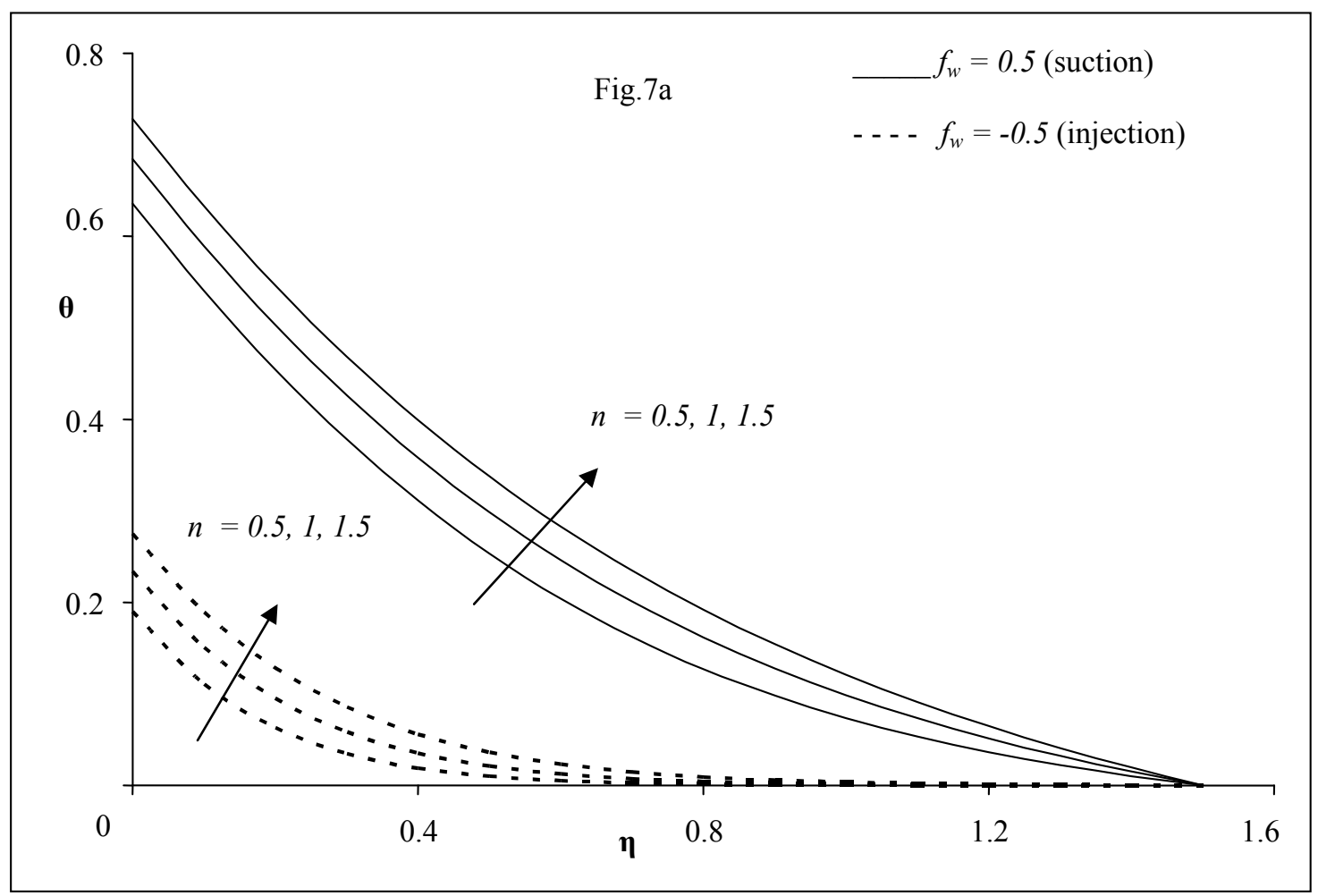




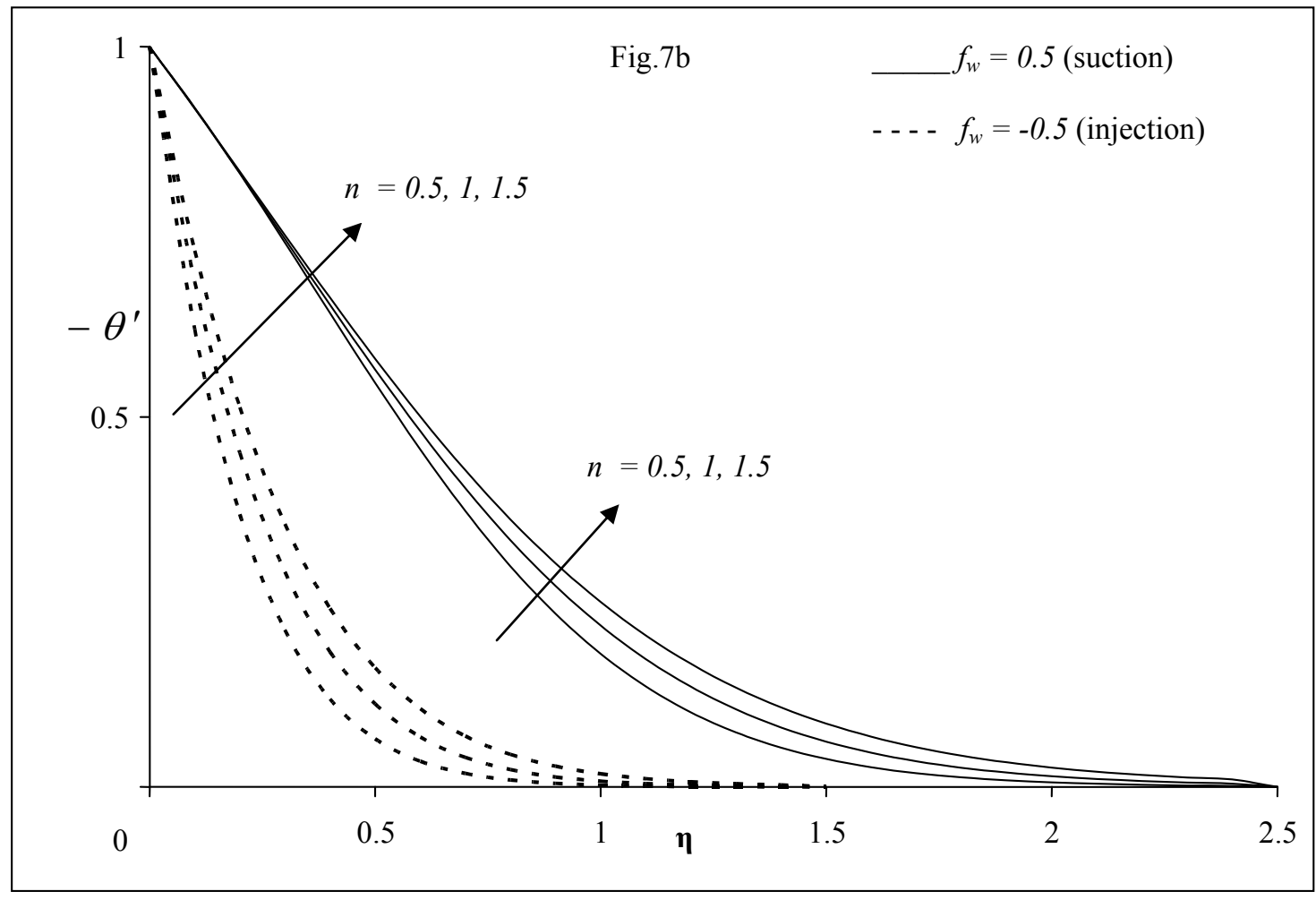

Fig.7. Variation of temperature profiles (a) $\theta$ and (b) $\theta^{\prime}$ with $M=0, \mathrm{Ec}=0, \operatorname{Pr}=10$ for different values of power law index $n$. $f_{w}=-0.5$ (injection) and - - - $f_{w}=0.5$ (suction).

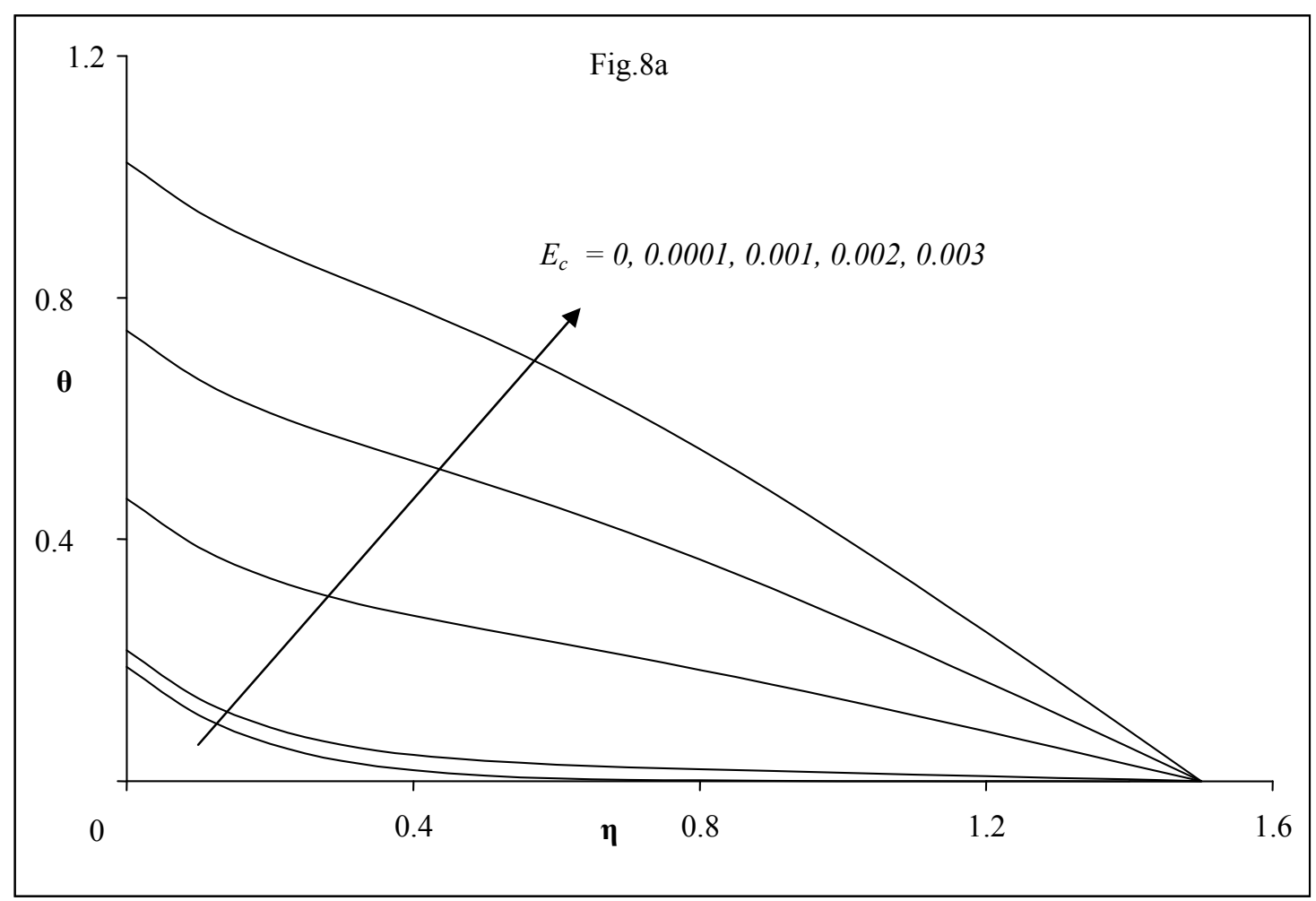




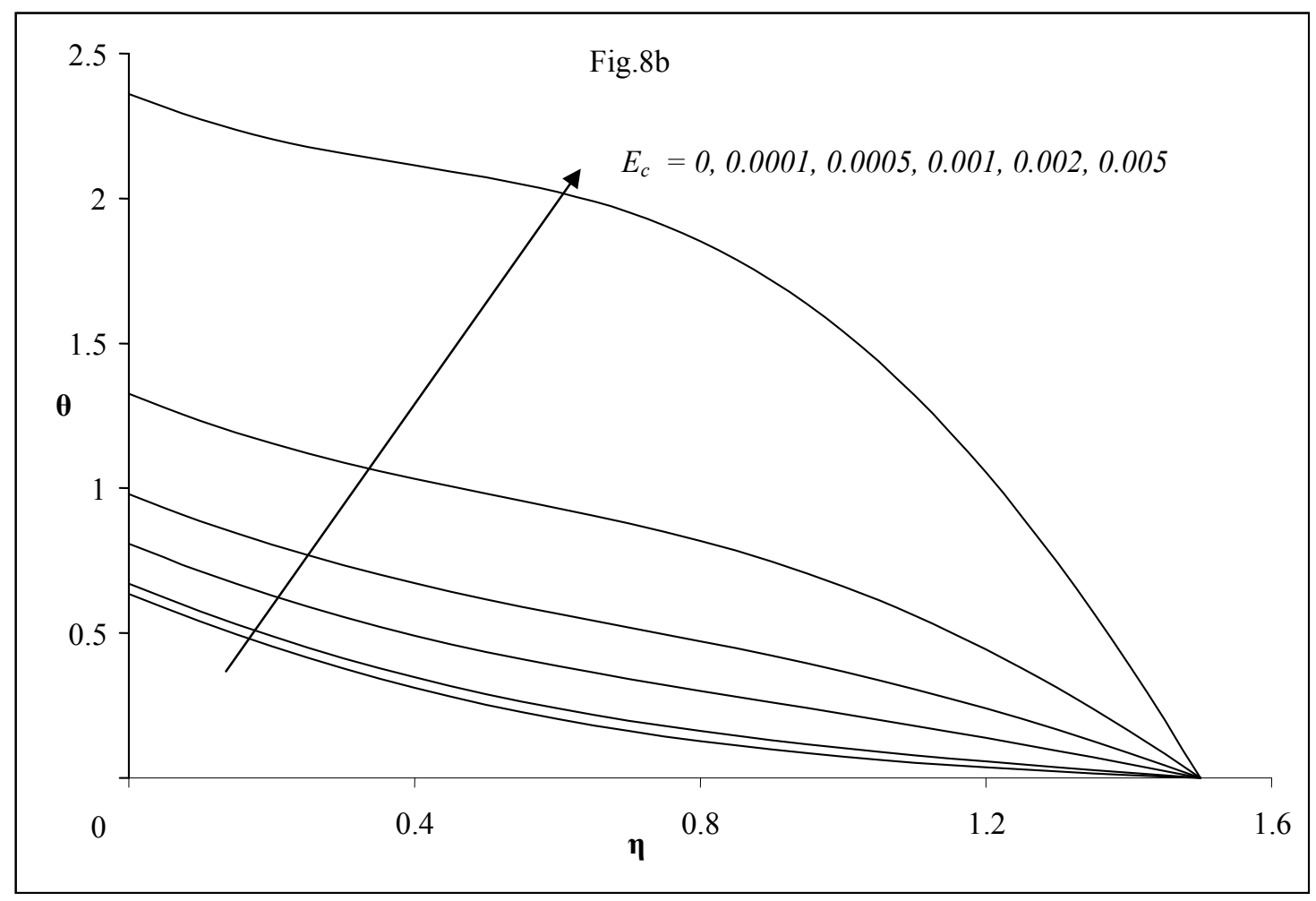

Fig.8. Variation of temperature profiles $\theta$ for pseudo plastic fluid $(n=0.5)$ with $M=0, \operatorname{Pr}=10$ for different values of Eckert number $\mathrm{E}_{\mathrm{c}}$. (a) $f_{w}=0.5$ (suction) and (b) $f_{w}=-0.5$ (injection).

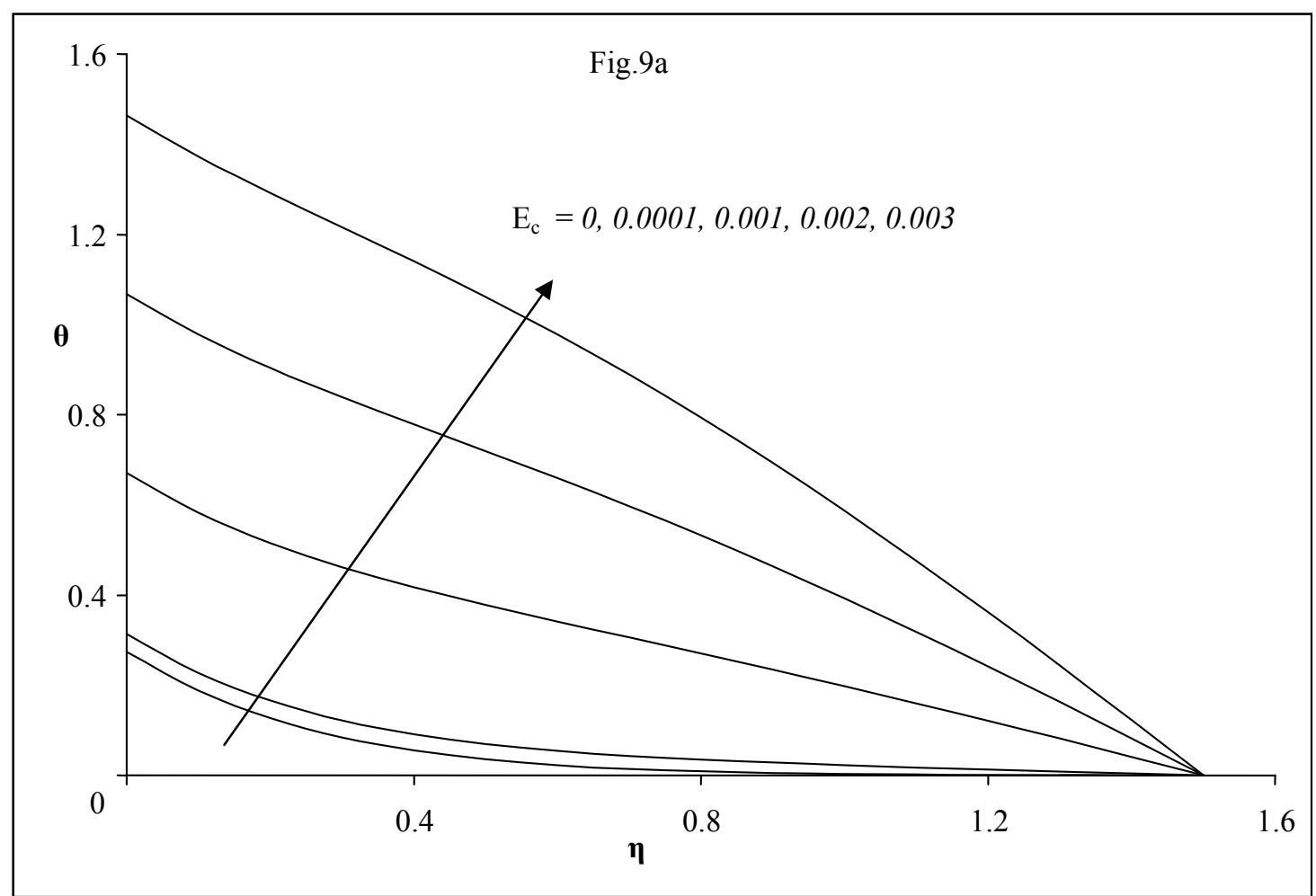




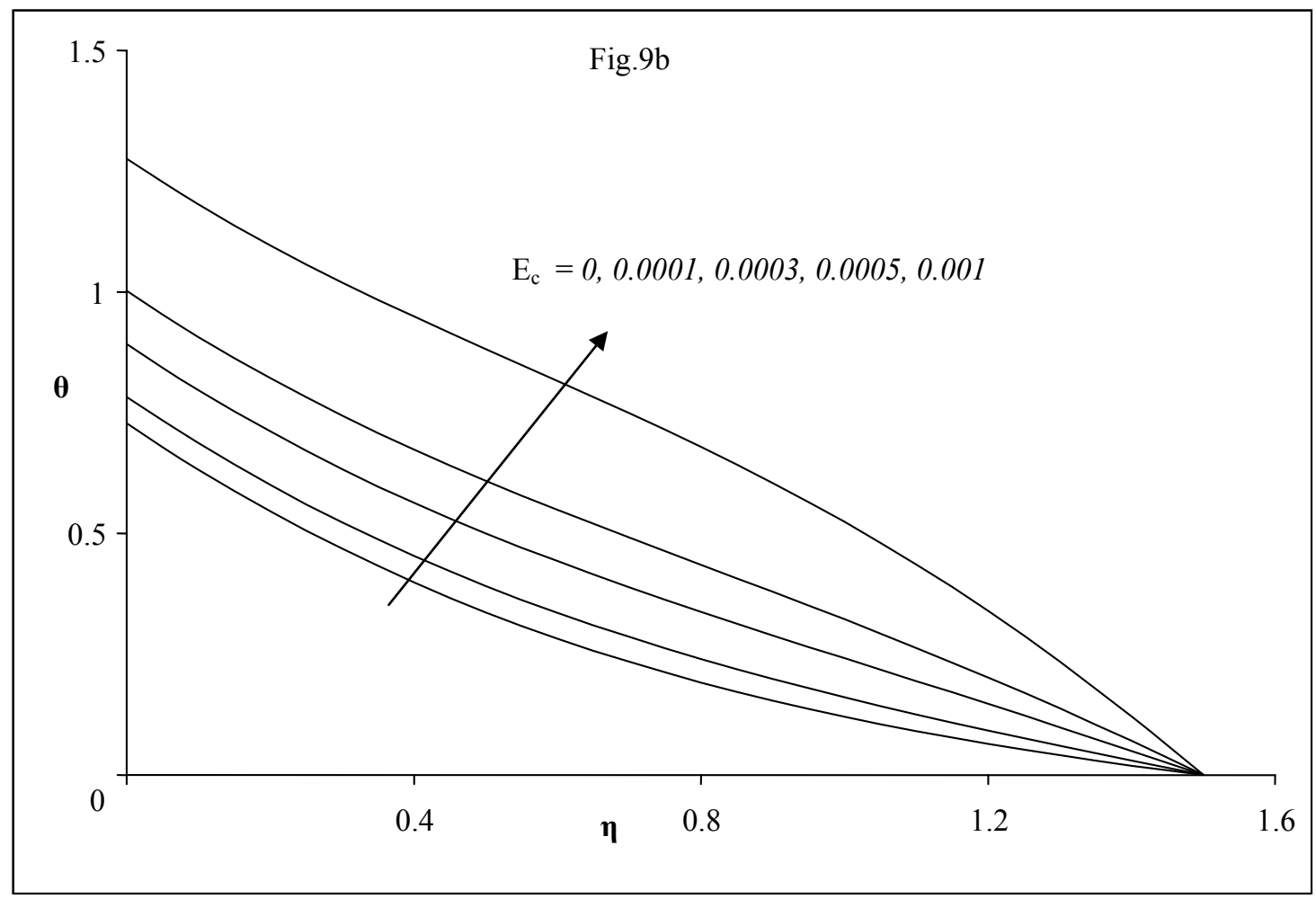

Fig.9. Variation of temperature profiles $\theta$ for dilatant fluid $(n=1.5)$ with $M=0, \operatorname{Pr}=10$ for different values of Eckert number $\mathrm{E}_{\mathrm{c}}$. (a) $f_{w}=0.5$ (suction) and (b) $f_{w}=-0.5$ (injection).

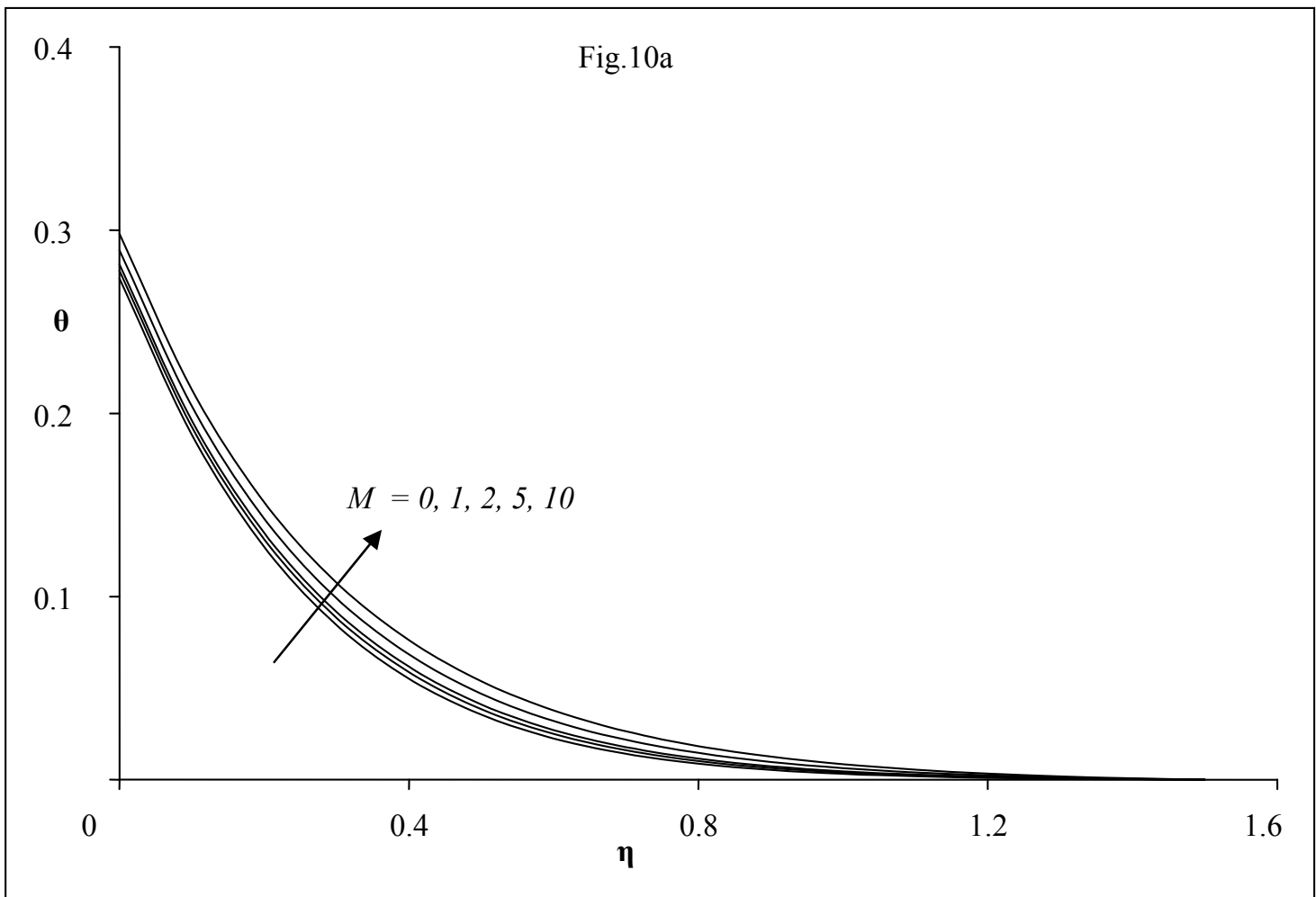




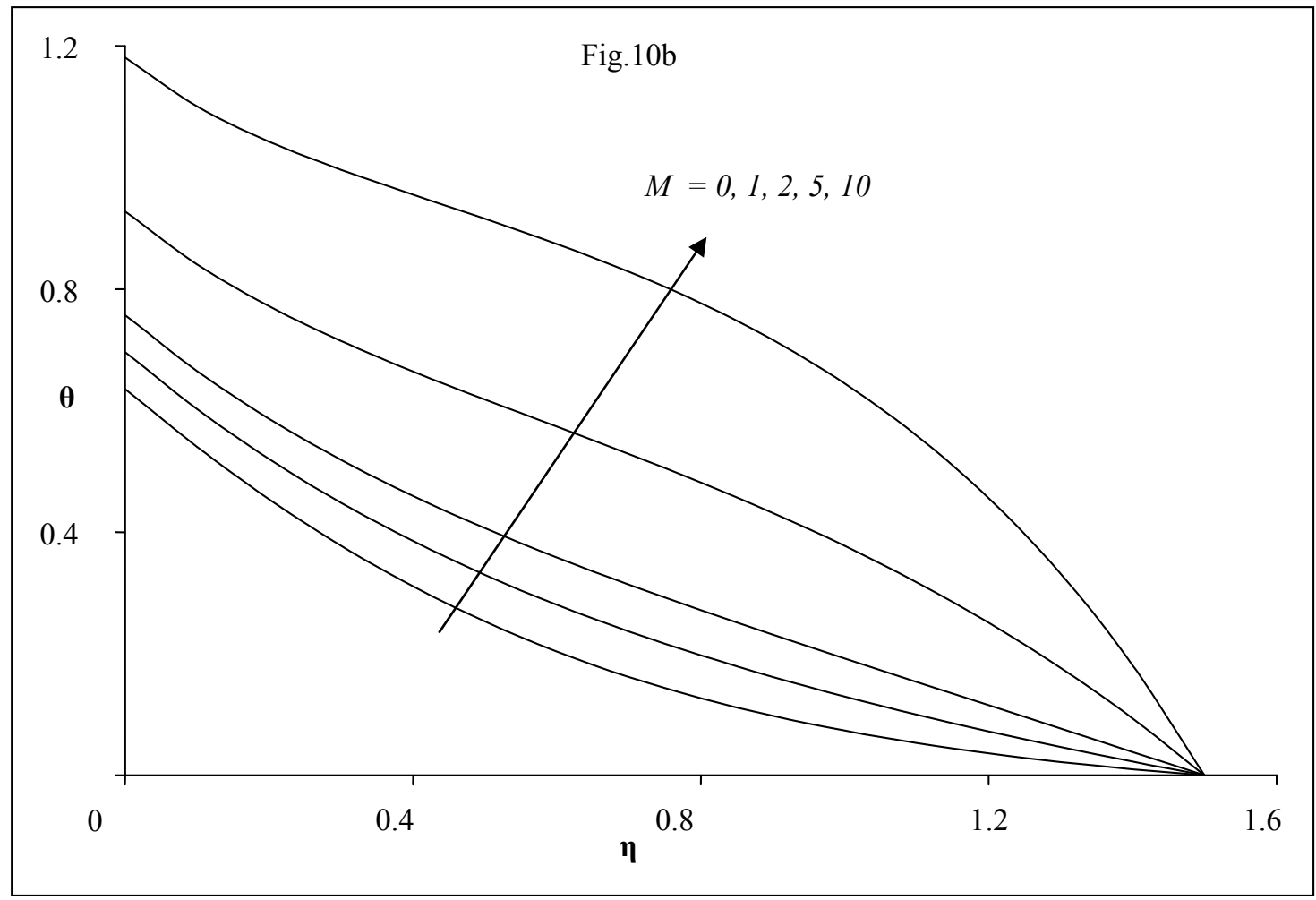

Fig.10. Variation of temperature profiles $\theta$ for pseudo plastic fluid $(n=0.5)$ with $\operatorname{Pr}=10$ and $\mathrm{Ec}=0$ for different values of magnetic field parameter $M$. (a) $f_{w}=0.5$ (suction) and (b) $f_{w}=-0.5$ (injection).

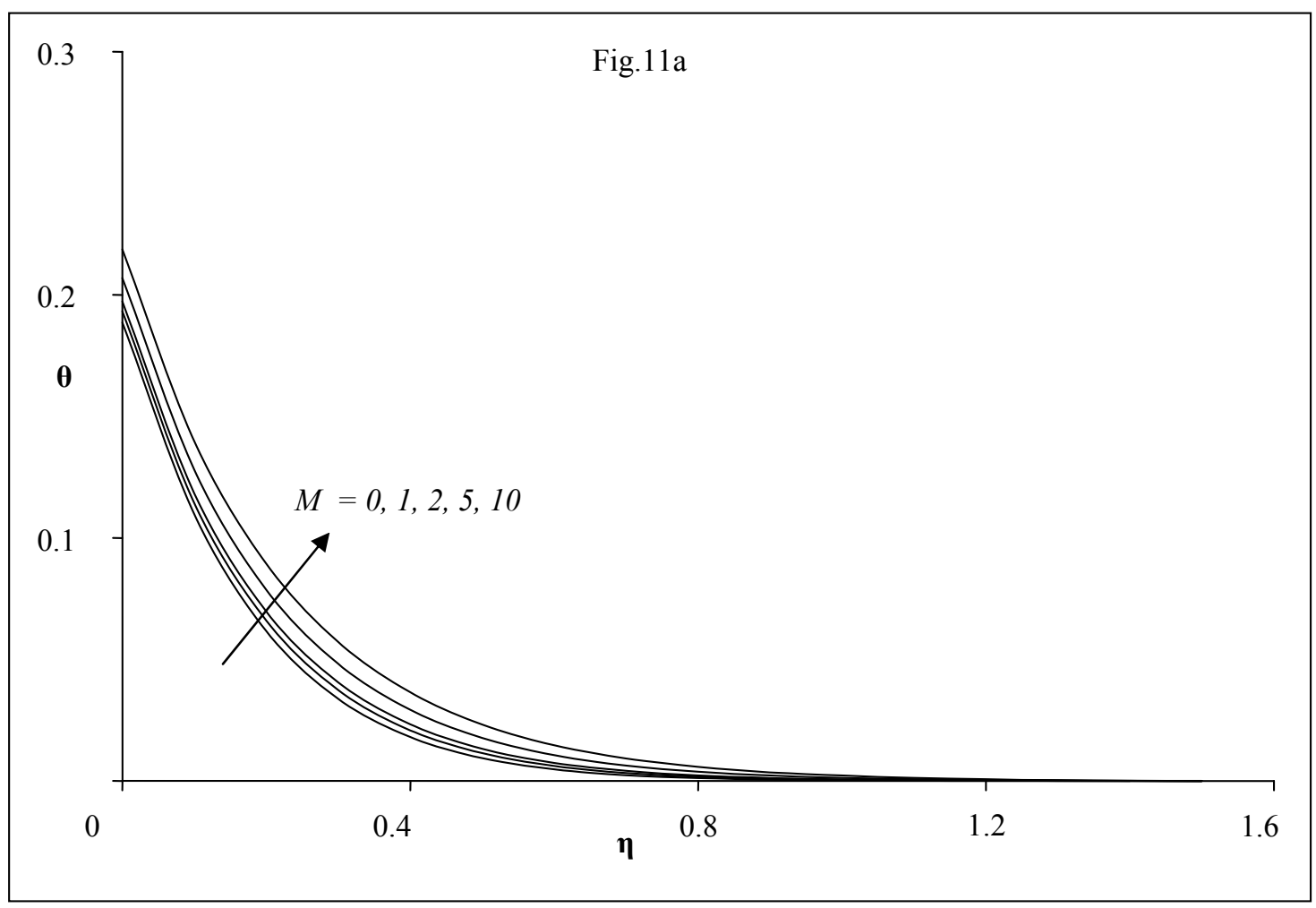




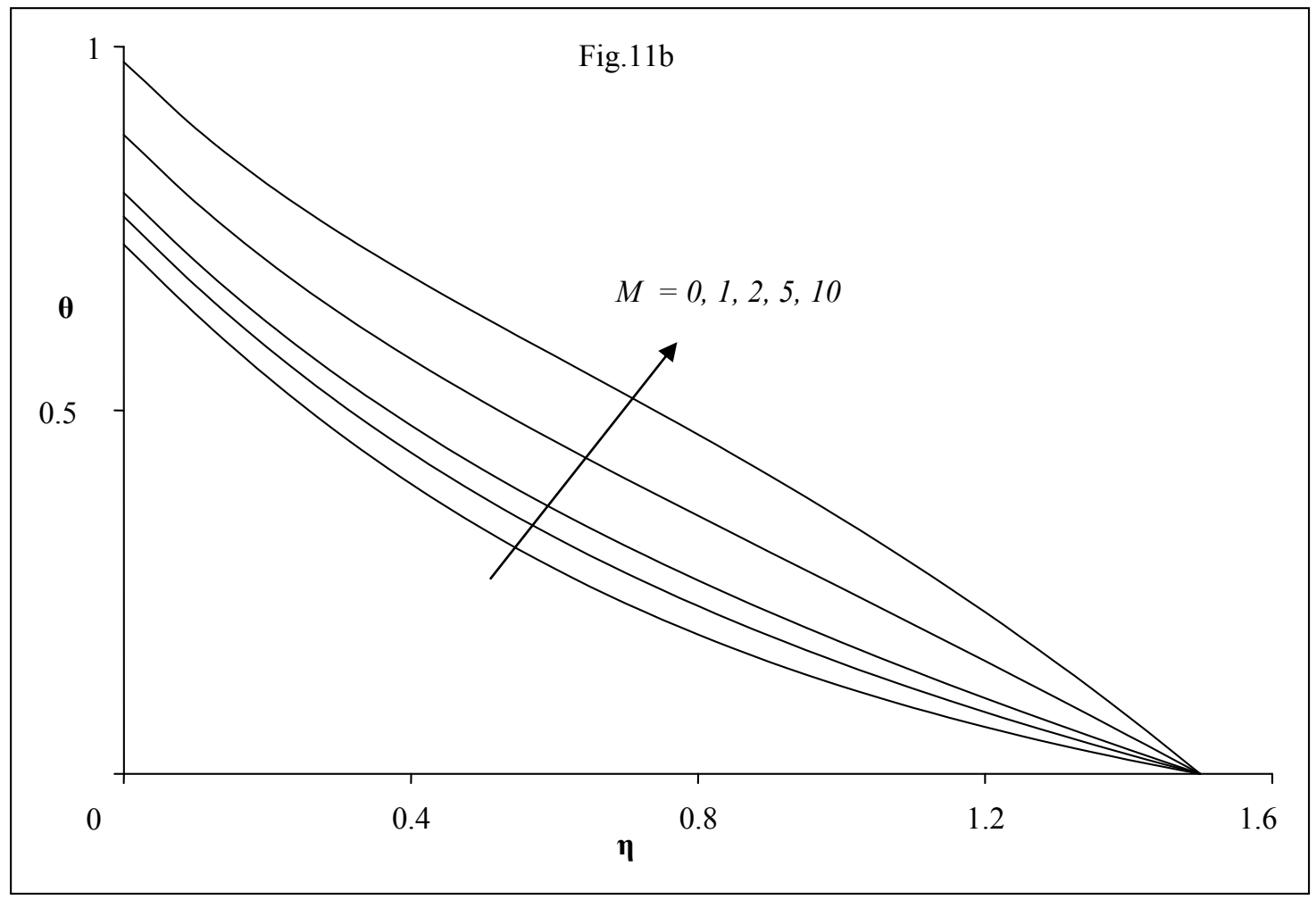

Fig.11. Variation of temperature profiles $\theta$ for dilatant fluid $(n=1.5)$ with $\operatorname{Pr}=10$ and $\mathrm{Ec}=0$ for different values of magnetic field parameter $M$. (a) $f_{w}=0.5$ (suction) and (b) $f_{w}=-0.5$ (injection).

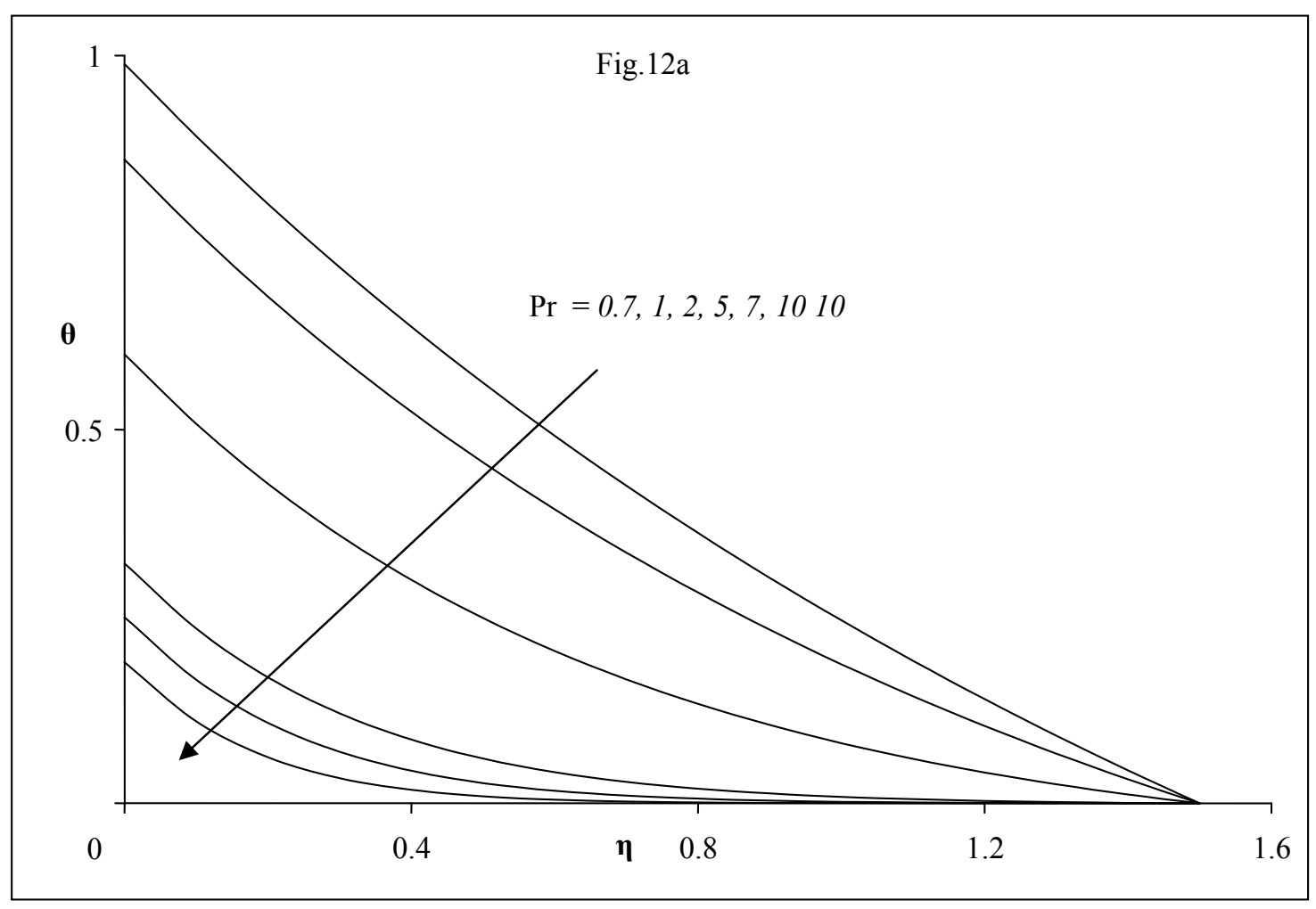




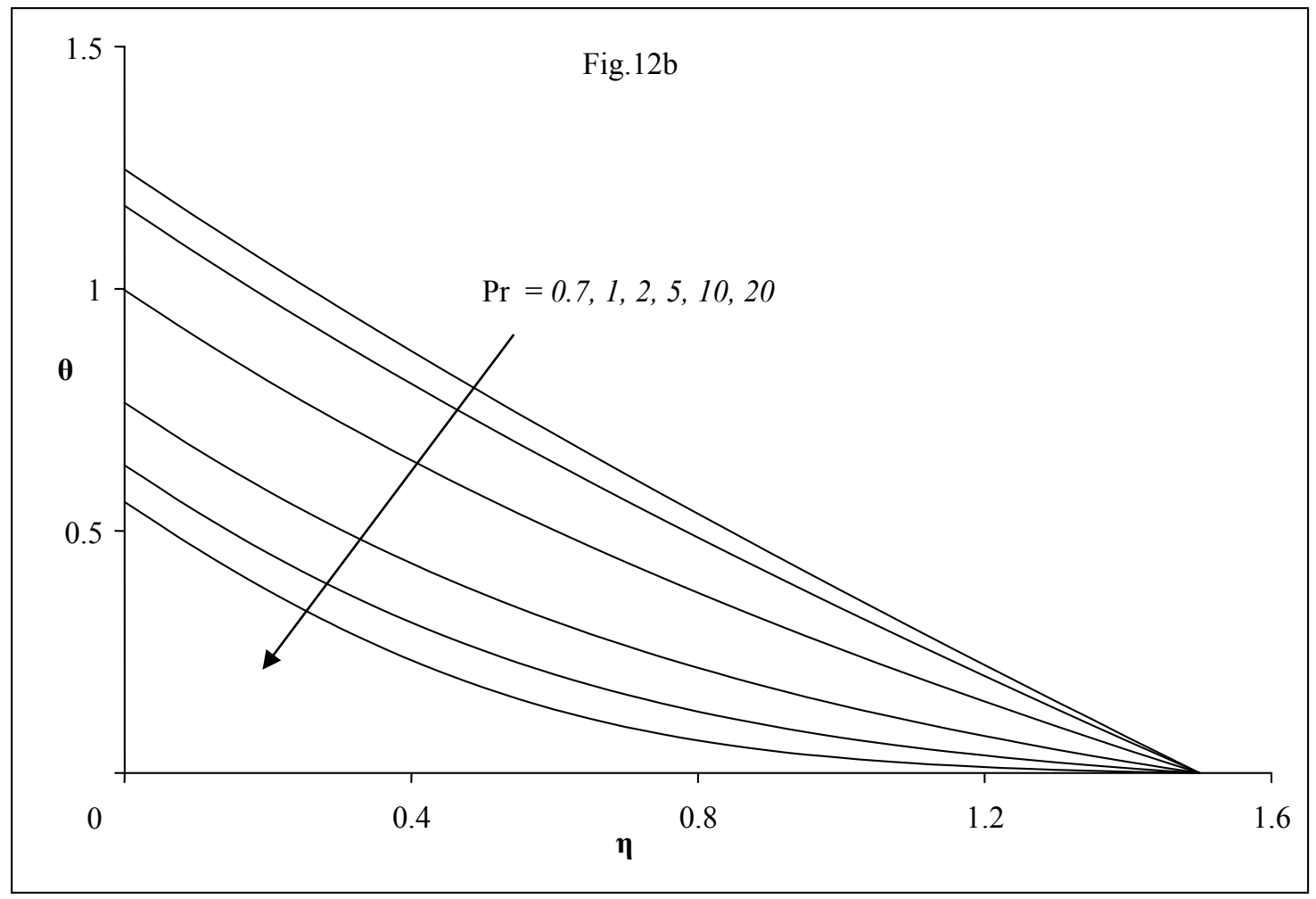

Fig.12. Variation of temperature profiles $\theta$ for pseudo plastic fluid $(n=0.5)$ with $M=0$ and $\mathrm{Ec}=0$ for different values of magnetic field parameter $M$. (a) $f_{w}=0.5$ (suction) and (b) $f_{w}=-0.5$ (injection).

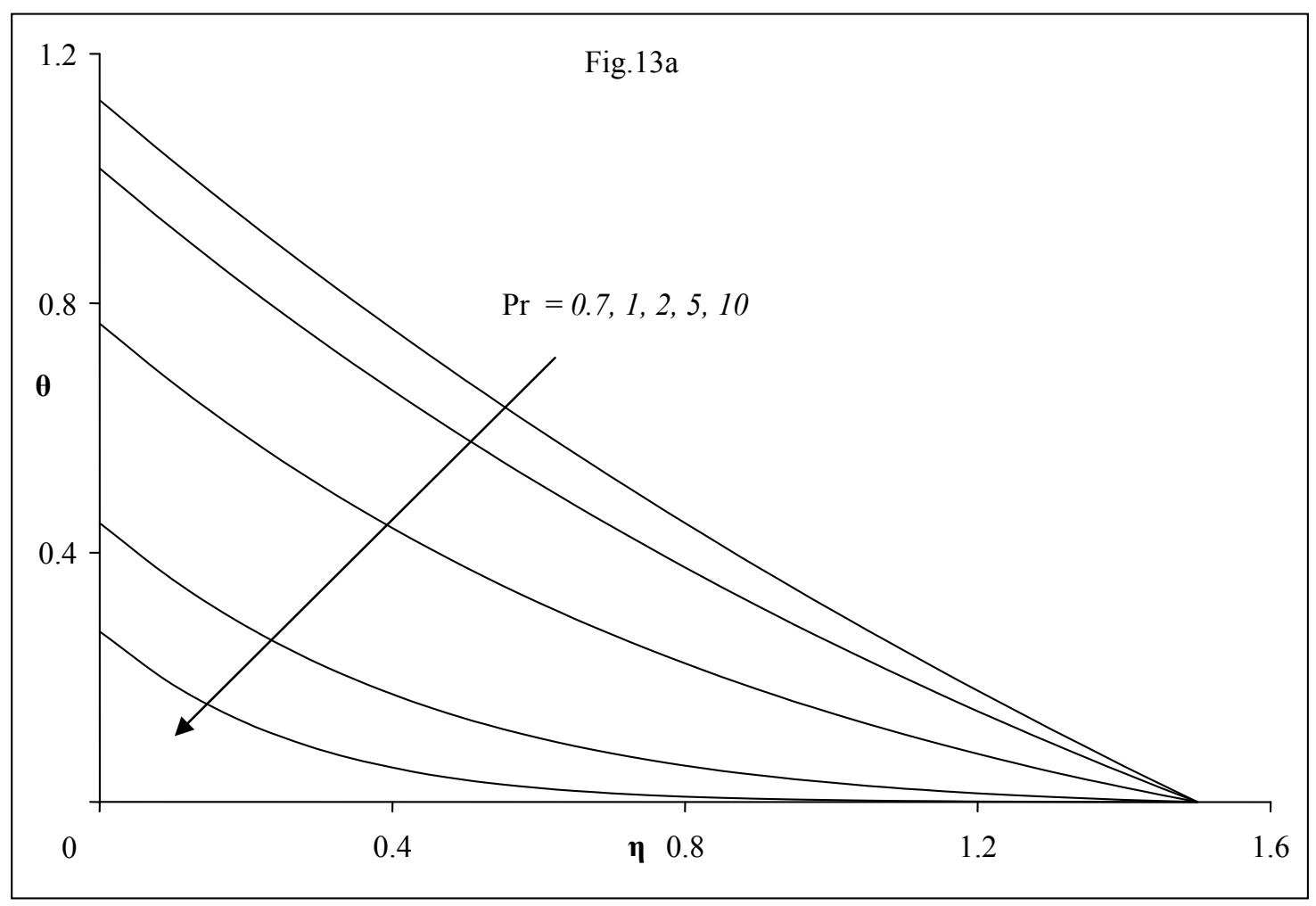




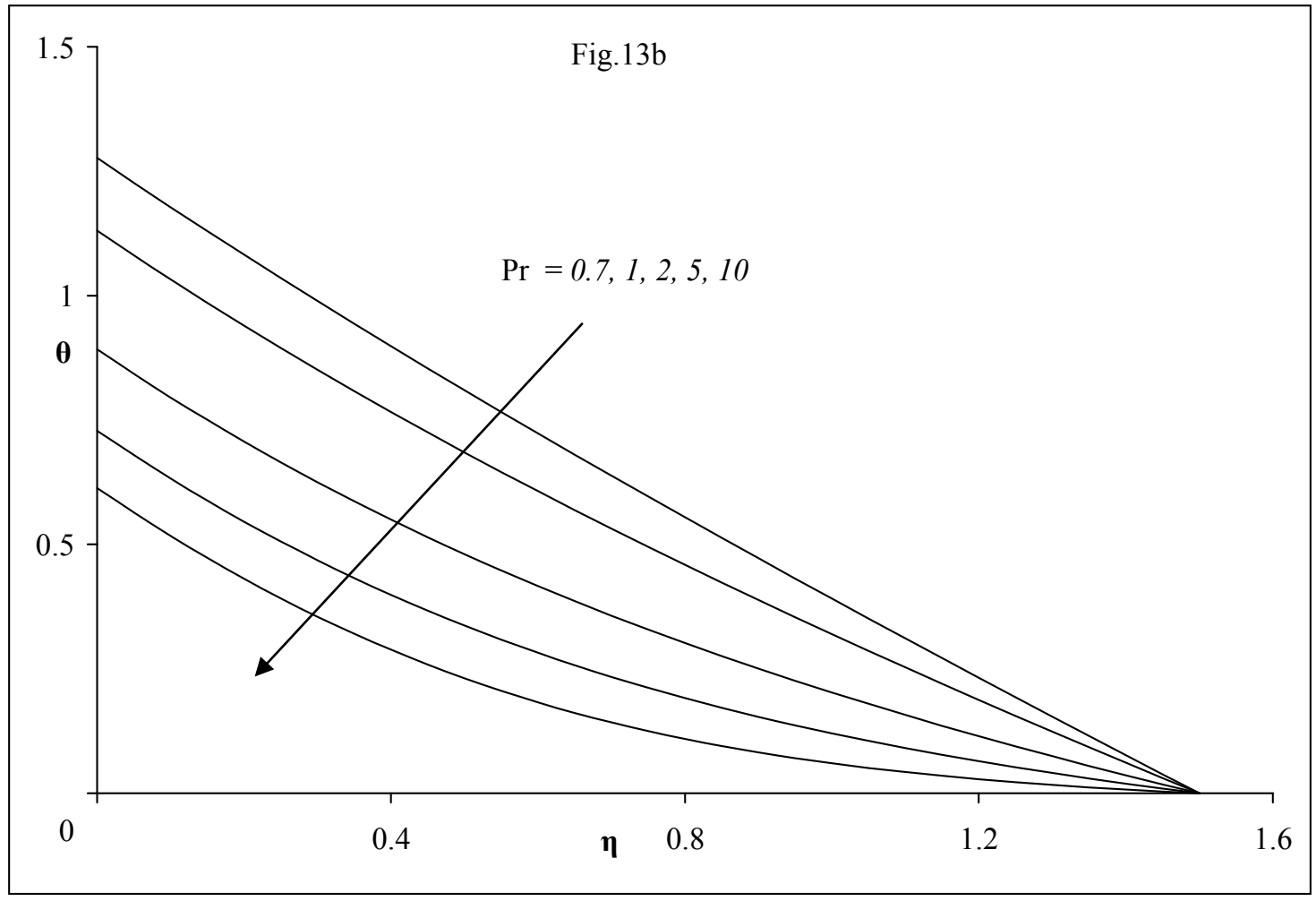

Fig.13. Variation of temperature profiles $\theta$ for pseudo plastic fluid $(n=1.5)$ with $M=0$ and $\mathrm{Ec}=0$ for different values of magnetic field parameter $M$. (a) $f_{w}=0.5$ (suction) and (b) $f_{w}=-0.5$ (injection).

\section{Acknowledgement}

The authors N. Kishan and B. Shashidar Reddy are thankful to the Osmania University for supporting this work under O.U-DST-PURSE programme, Osmania University, Hyderabad, Andhra Pradesh, INDIA.

\section{Nomenclature}

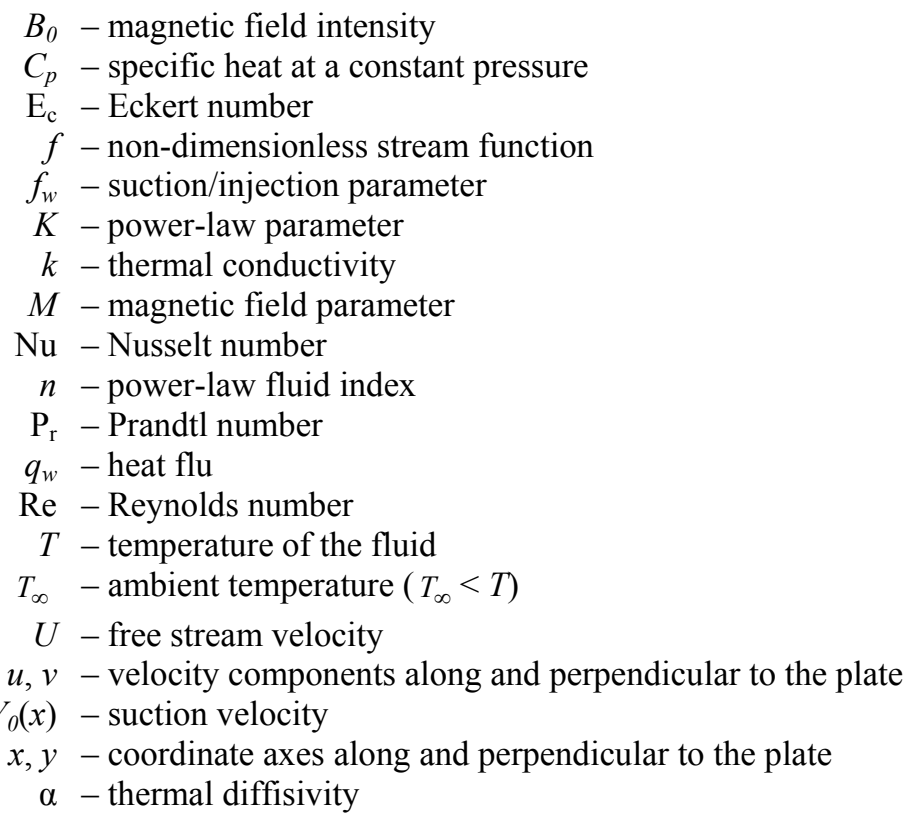


$\gamma$ - kinematic viscosity

$\eta$ - dimensionless similarity variable

$\theta$-dimensionless temperature

$\mu$ - magnetic permeability

$\rho$ - density

$\sigma$ - electrical conductivity

$\tau_{w}$ - shearing stress on the surface

$\psi-$ stream function

\section{References}

Acrivos A. (1960). A theoretical analysis of laminar natural convection heat transfer to non-Newtonian fluids. AIChEJ, vol.6, pp.584-590.

Acrivos A., Shah M.J. and Petersen E.E. (1960): Momentum and heat transfer in laminar boundary layer flows of nonNewtonian fluids past external surfaces. - AIChEJ, vol.6, pp.312-317.

Bellman R.E. and Kalaba R.E. (1965). Quasi-Linearization and Non-Linear Boundary Value Problems. - New York: Elsevier.

Andersson H.I., Bech K.H. and Dandapat B.S. (1992): Magnetohydrodynamic flow of a power-law fluid over a stretching sheet. - Int. J. Non-Linear Mech., vol.27, pp.929-936.

Cortell R. (2005): A note on magnetohydrodynamic flow of a power-law fluid over a stretching sheet. - Appl. Math. Comput., vol.168, pp.557-566.

Fox V.G., Erickson L.E. and Fan L.T. (1969): The laminar boundary layer on a moving continuous flat sheet immersed in a non-Newtonian fluid. - AIChEJ., vol.15, pp.327-333.

Howell T.G., Jeng D.R. and De Witt K.J. (1997): Momentum and heat transfer on a continuous moving surface in a power-law fluid. - Int. J. Heat Mass Transfer, vol.40, pp.1853-1861.

Jadhav B.P. and Waghmode B.B. (1990): Heat transfer to non-Newtonian power-law fluid past a continuously moving porous flat plate with heat flux. - Warme and Stoffubertragung, vol.25, pp.377-380.

Lee S.Y. and Ames W.F. (1960): Similarity solutions for non-Newtonian fluids. - AIChEJ., vol.12, pp.700-708.

Lin Hisio-Tsung and Shih Yen-Ping. (1980): Laminar boundary layer heat transfer to power-law fluids. - Chem. Eng. Commun., vol.4, pp.557-562.

Mahmoud M.A.A. and Mahmoud M.A.E. (2006): Analytical solutions of hydro-magnetic boundary layer flow of a nonNewtonian power-law fluid past a continuously moving surface. - Acta Mechanica, vol.181, pp.83-89.

Murthy T.V.R. and Sharma Y.V.B. (1985): Heat transfer in flow past a continuously moving porous flat plat with heat flux. - Warme-Stoffubertrag, vol.20, pp.39-42.

Rao J.H., Jeng D.R. and De Witt K.J. (1999): Momentum and heat transfer in a power-law fluid with arbitrary injection/suction at a moving wall. - Int. J. Heat Mass Transfer, vol.42, pp.2837-2847.

Sakiadis B.C. (1961): Boundary layer behavior on continuous solid surface; The boundary layer on a continuous moving surface. - AIChEJ., vol.7, pp.26-28.

Schowalter W.R. (1960): The application of boundary-layer theory to power-law pseudo plastic fluid: similar solutions. - AIChEJ., vol.6, pp.24-28.

Sundaram K.M. and Nath G. (1976): Heat transfer to electrically conducting power-law in the thermal entrance region with constant heat flux. - Proc. Indian Acad. Sci., vol.83A, No.2, pp.50-64.

Tsou F.K., Sparrow E.M. and Goldstein V. (1967): Flow and heat transfer in the boundary layer on a continuous moving surface. - Int. J. Heat Mass Transfer, vol.10, pp.219-235.

Received: December 21, 2011

Revised: August 23, 2012 